\title{
Gerechtigkeit für Odoardo Galotti
}

\section{Ein Theatercoup mit Folgen: Wie Lessing das tragische Opfer geschlechteranthropologisch umwidmet und damit von Bodmer bis zur Gegenwart wirkt}

\author{
Uwe C. Steiner
}

Angenommen: 21. Januar 2021 / Online publiziert: 16. Februar 2021

(C) Der/die Autor(en) 2021

Zusammenfassung Der tragische Schluss der Emilia Galotti hat von Anfang an gespaltene Reaktionen hervorgerufen. Noch heute sind zahlreiche Missverständnisse im Umlauf. Stimmen, die seine fragwürdige Konstruktion bemängelten, verklangen bald. Stattdessen wurde nach Verantwortlichen für die Katastrophe gefahndet. Dass schon bald der Vater, Odoardo Galotti, in Haftung genommen wurde, liegt, so die These, nicht zuletzt an einer Umwidmung oder Neukonzeption des tragischen Opfers. Es wird mit zentralen Versatzstücken der zeitgenössischen Geschlechtersemantik aufgeladen und einer metadramaturgischen Reflexion unterzogen. Emilias Selbstopfer ist ein Opfer im Wortsinn, es stattet die victima mit allen Attributen des sacrificiums aus. Und es ist ein Opfer, das maßgeblich von der Figur selbst in die Wege geleitet und vollzogen wird. Ein Großteil der nachfolgenden Dramatik arbeitet sich unter Übernahme der geschlechteranthropologischen Prämissen an diesem fulminanten Ende ab. Die Unterminierung einer bürgerlichen Würdekultur durch eine bald sich etablierende Kultur des Opfers setzte schon damals ein. Tatsächlich dokumentiert das Stück eine Krise der Tragödie. Wenn schon das Opfer selbst eine Darstellungsfunktion besitzt, dann steht bis heute zur Debatte, welche Funktion die Darstellung des Opfers besitzt.

U. C. Steiner $(\bowtie)$

Institut für Neuere deutsche Literatur- und Medienwissenschaft, FernUniversität in Hagen, 58084 Hagen, Deutschland

E-Mail: Uwe.Steiner@fernuni-hagen.de 


\title{
Justice for Odoardo Galotti
}

A coup de theâtre and its consequences: How Lessing repurposes tragic sacrifice within a frame of gender anthropology, producing a lasting effect from Bodmer until now

\begin{abstract}
Ever since, the tragic ending of Emilia Galotti has stimulated divided reactions. Even today numerous misreadings occur. Voices which criticized its questionable or yet dubious construction soon faded. Instead of that, responsibles have been searched for. Especially Odoardo Galotti, Emilia's father, has been taken into accountability. The reason for this, thus the claim, lies in a new conception of tragic sacrifice. It is being charged with central elements of contemporary gender anthropology. Furthermore, it undergoes a metadramaturgic reflection. Emilia's self-sacrifice represents a genuine »Opfer« in the literal senses of victima and sacrificium. Actually, this sacrifice is significantly initiated and performed by the character itself. A major part of subsequent dramatic production is adopting the tragedy's premises on gender anthropology while commenting on the fulminant ending. It is as early as this that a bourgeois culture of dignity is being undermined by a victimhood culture. The drama does in fact document a crisis of tragedy itself. If already sacrifice possesses a dimension of representation, a further question remains yet unanswered: Which function does (dramatic) representation of sacrifice fulfill?
\end{abstract}

»Nicht Sie, mein Vater - Ich selbst - ich selbst-«

(Emilia Galotti, Sz. V/8)

\section{I.}

Mit dem tragischen Schluss der Emilia Galotti gelang Gotthold Ephraim Lessing ein veritabler Theatercoup. ${ }^{1}$ Dass ein Vater seine Tochter erdolcht, und zwar auf ihren Wunsch hin, das löste einen Eklat aus, der nicht nur dem bürgerlichen Trauerspiel, damals längst eine Modegattung, einen anhaltenden Konjunkturschub verpasste. Von der Uraufführung 1772 und der Erstpublikation im gleichen Jahr an sollte das ebenso effektvolle wie anstößig empfundene Ende nicht mehr aufhören, die Gemüter zu bewegen. Seine Schockwellen teilte es der gesamten nachfolgenden dramatischen Produktion mit. Seither ist es um das Skandalon nicht mehr still geworden. Zwar scheint jeder Satz des Dramas mittlerweile hundertfach hin und her gewendet. ${ }^{2}$ Dennoch gingen im allgemeinen Geräusch um die väterliche Beihilfe zum Suizid einige Besonderheiten dieser Lösung des tragischen Knotens unter. ${ }^{3}$

\footnotetext{
1 Vgl. Brigitte Prutti, »Coup de Théâtre - Coup de Femme or What is Lessing's Emilia dying from?«, Lessing Yearbook XVI/26 (1994), 1-28.

2 Monika Fick, Lessing-Handbuch. Leben - Werk - Wirkung, Vierte Aufl., Stuttgart 2016, 347.

3 Zwei Aufsätze des Verf. deuten die hier ausgeführten Überlegungen an: »>Für sich und andre vielleicht.< Ottilies Selbstsakralisierung und die Lessing-Kritik in Goethes Wahlverwandtschaften«, in: Hannah Din-
} 
So wurde eine metadramatisch aufgeladene Wendung bis heute kaum gewürdigt, obwohl sie doch so auffällig am Schluss des Dramas begegnet. Als der Verführer und sein intriganter Helfer, als der Prinz und sein Höfling Marinelli die Titelheldin nur noch sterbend antreffen, zieht Odoardo Galotti, Vater der Emilia, nicht die naheliegende Konsequenz. Er habe nicht vor, sagt er, »den Stahl wider [sich] selbst [zu] kehren [...], um [s]eine Tat wie eine schale Tragödie zu beschließen« (V/8; 371; Hv. U. St.). ${ }^{4}$ Auf der Ebene der Handlung leuchtet dieser Schluss ein. Odoardo verzichtet darauf, sich selbst dafür zu richten, dass er soeben das ihm Liebste getötet hat. Stattdessen wird er sich vor dem Gericht verantworten, dem der zutiefst in die Tat Verstrickte, dem der Prinz, der Verführer, vorsitzen wird. So würde sich der Richter als Täter erweisen müssen. Wichtiger aber noch und in ihren Konsequenzen bislang nicht ausgelotet erscheint die gattungsreflexive Volte in Odoardos Worten. Eine dramatische Figur gebraucht auf der Theaterbühne einen dramenpoetologischen Begriff, den der Tragödie, und zwar in dem Moment, in dem das Trauerspiel wirklich dabei ist, zu enden. Hätte sich der Vater selbst gerichtet, wäre es seine Tragödie geworden und wir sprächen über ein Drama mit dem Titel »Odoardo Galotti«. Zwar hatte die Gattungskonvention des bürgerlichen Trauerspiels das Monopol der weiblichen Figuren, insbesondere der Töchter, auf die Position des tragischen Helden längst errichtet. Aber warum begibt sich hier ein Vater explizit des Privilegs, tragischer Held zu sein? Welche Konsequenzen hat es für die Wahrnehmung der Figur gezeitigt? Und warum durchbricht Lessing mit dieser metapoetischen Aussage quasi die vierte Wand? Warum bewegt sich eine dramatische Figur aus dem vom Wirkungsästhetiker eigentlich angestrebten illusionistischen Kontinuum hinaus und appelliert an Instanzen außerhalb der Bühne? Das berührt auch die Frage nach der poetischen Gerechtigkeit. ${ }^{5}$ Indem Lessings Drama hier Verzicht leistet, überschreitet es die ästhetische zugunsten einer politischen Dimension. ${ }^{6}$ Zunächst, das ist zu zeigen, tritt an die Stelle des fürstlichen Richters das Urteil der Rezeptionsgeschichte. Urteilt sie womöglich gerechter als der in die Tat verstrickte Adlige richten würde, wenn sie, freilich mit einer gewissen Konsequenz, schon früh und dann anhaltend den bedauernswerten Vater auf die Anklagebank zitiert?

In diesem Sinne soll der vielleicht etwas plakativ geratene Titel »Gerechtigkeit für Odoardo Galotti« verstanden werden. Dass der Verzicht auf die Position des

geldein, Anna-Katharina Gisbertz, Sebastian Zilles, Justus Fetscher (Hrsg.), Schwellenprosa. (Re-)Lektüren zu Goethes Wahlverwandtschaften, München 2018, 87-104. Ferner: »Die Entsorgung des Hausvaters. Geschlechtersemantik in Dramen Großmanns, von Gemmingens und in Lessings Emilia Galotti«, in: Martin Dinges (Hrsg.), Männlichkeiten und Care. Selbstsorge, Familiensorge, Gesellschaftssorge, Weinheim, Basel 2020, 146-163.

4 Zitate aus der Emilia Galotti werden im Folgenden mit Akt- und Szenenziffer nachgewiesen. Es folgt die Seitenzahl der Ausgabe Gotthold Ephraim Lessing, Werke und Briefe in zwölf Bänden, hrsg. Wilfried Barner u.a., VII.

5 Vgl. Cornelia Mönch, Abschrecken oder Mitleiden. Das deutsche bürgerliche Trauerspiel im 18. Jahrhundert. Versuch einer Typologie, Tübingen 1993, $29 \mathrm{ff} ., 41-43,151 \mathrm{ff}$.

6 Vgl. Ulrich Schödlbauer, »Wie politisch ist die Kunst?«, in: Werner Daum, Wolfgang Kruse, Eva Ochs, Arthur Schlegelmilch (Hrsg.), Politische Bewegung und symbolische Ordnung. Festschrift für Peter Brandt, Bonn 2014, 59-75, hier: 67. Dass die Emilia »zugleich eine häusliche Tragödie und ein politisches Drama« darstellt, hat Bengt Algot Sørensen, Herrschaft und Zärtlichkeit. Der Patriarchalismus und das Drama im 18. Jahrhundert, München 1984, 92 f. herausgestrichen. 
tragischen Helden den Vater nicht davor bewahrt hat, zum Sündenbock ganzer Deutungstraditionen zu werden, soll hier nicht beklagt, als vielmehr verstanden werden. Es geht um die Rekonstruktion einer Ästhetik und ihrer Wirkung, die die herkömmliche, »schal« gewordene Tragödie abwertet, weil sie die Position des tragischen Helden opferpolitisch und geschlechteranthropologisch neu begründet. Sie wirkt darin bis heute nach.

Das mag erklären, warum kaum eine Rezeptionsgeschichte eines kanonischen Werks so ausführlich befragt wurde wie die der Emilia. ${ }^{7}$ So hatte man die schlechthin souveräne Konstruktion des $»$ Dings von einer Tragödie $\ll^{8}$ sofort bewundert oder früh schon kritisiert. ${ }^{9}$ Beinah lückenlos, so schien es, greife jedes Ereignis ineinander: Nichts auf der Bühne, das nicht motiviert geschehe. Das musste auch dem tragischen Schluss den Anschein zwingender Notwendigkeit verleihen. Aber nicht bei allen: Des Öfteren wurde moniert, Lessing habe den skandalösen Schluss und damit die tragische Katastrophe nicht hinreichend motiviert. ${ }^{10}$ Eine Braut, die angesichts der noch nicht erkalteten Leiche ihres Verlobten über ihr warmes, anscheinend für den Verführer glühendes Blut raisonniert, ein Vater, der, anstatt den Prinzen zu attackieren und $»$ mit dem Dolch in der Hand sich und seinem Kinde den Ausweg aus dem Schloß zu suchen«, die eigene Tochter meuchelt, diese überraschende Lösung befremdete nicht erst Gustav Freytag ${ }^{11}$, sondern schon viele Besucher der ersten Aufführungen. Ihnen, die Effekte der Rührung erwartet hatten, mutete das Stück das Grässliche zu. Der Wirkungsästhetiker Lessing hatte das Mitleid, das er hervorrufen wollte, mit einer beträchtlichen Portion Jammer und Schauder unterfüttert. ${ }^{12}$ Auf die unmittelbaren Reaktionen der Zuschauer und Leser folgte die produktive Rezeption ${ }^{13}$ auf der Bühne selbst. Hier reagierten Nachahmer, Fortführer, Radikalisierer und Gegner auf Lessings Dramaturgie, arbeiteten sich bürgerliches Rührstück, Stürmer und Dränger, Goethe, Schiller, Kotzebue bis zu Hebbel und darüber hinaus an der Neukonzeption des tragischen Opfers ab.

\footnotetext{
7 Vgl. Fick (Anm. 2). Edward Dvoretzky, Lessing. Dokumente zur Wirkungsgeschichte 1755-1968, 2 Bde., Göppingen 1971. Gunter E. Grimm, Rezeptionsgeschichte. Grundlegung einer Theorie, München 1977.

8 Lessing am 10. Febr. 1772 an Karl Lessing. Gotthold Ephraim Lessing, Werke und Briefe in zwölf Bänden, hrsg. Wilfried Barner u.a., XI/2: Briefe von und an Lessing 1770-1776, hrsg. Helmuth Kiesel u.a., Frankfurt a.M. 1988, 351.

9 Vier Monate nach der Uraufführung, am 10. Juli 1772, schreibt Goethe an Herder: »Emilia Galotti ist [...] nur gedacht, und nicht einmal Zufall oder Caprice spinnen irgend drein.« Weimarer Ausgabe, IV. Abteilung: Goethes Briefe, Bd. 1-50, Weimar 1887-1912, II, 19. Lessings Tragödie sei ein »in Schweiß und Pein producirtes Meisterstück des reinen Verstandes [...] unstreitig ein großes Exempel der dramatischen Algebra«. So Friedrich Schlegel, »Über Lessing«, in: Ders., Kritische Friedrich-Schlegel-Ausgabe, hrsg. Ernst Behler, Jean-Jacques Anstett, Hans Eichner, Zürich 1958 ff., 1. Abteilung, II, 116.

10 Von einem »Defizit an pragmatischer Motivierung des von Lessing gewählten Schlusses« sprechen Wilfried Barner, Gunter E. Grimm, Helmuth Kiesel und Martin Kramer, Lessing. Epoche - Werk - Wirkung, 5. Aufl., München 1987, 218.

11 Gustav Freytag, Die Technik des Dramas. Zweite, verbesserte Aufl., Leipzig 1872, 261.

12 Das Verhältnis zwischen der Mitleidsdramaturgie des bürgerlichen Trauerspiels und der klassizistischen Abschreckungstragödie ist kontrovers diskutiert worden. Vgl. Mönch (Anm. 5). Dagegen Karl S. Guthke, Das deutsche bürgerliche Trauerspiel, 6. Aufl., Stuttgart, Weimar 2006, XI u.ö.

13 So nennt sie Grimm (Anm. 7), 180.
} 
Der folgende Abschnitt II beleuchtet, wie sich im Verlaufe der Rezeption die Wahrnehmung von der Darstellung auf das Dargestellte verschiebt und bald vornehmlich Odoardo für die Katastrophe in Haftung genommen wird. Darauf wird gezeigt, dass die theatralische Tötung einer unschuldigen jungen Frau weder einen Mord, schon gar keinen Ehrenmord darstellt. Sie bringt vielmehr, so meine These, erstens ein Opfer im vollen Wortsinn auf die Bühne, ein Sacrificium, ein Opferritual in theatralischer Brechung. (Abschnitt III) Die Signifikanz dieses dramatischen Opfers, und damit ein Grund seiner theatralischen Wirkung, erschließt sich erst, so der zweite Teil dieser These, wenn man die in ihm zumindest für die Zeitgenossen deutlichst mitschwingenden geschlechteranthropologischen Resonanzen heraushört. Mehr noch, die im Stück artikulierte Geschlechtersemantik geht eine enge Verbindung mit der zu Beginn angesprochenen metadramatischen Selbstreflexion ein. (Abschnitt IV) Das stößt, drittens, eine sofort einsetzende produktive Rezeption an, die sich in Anknüpfung, Radikalisierung oder im Gegenentwurf dieser Verbindung zwischen der Umwidmung des dramatischen Opfers und der zeitgenössischen Geschlechtersemantik verschreibt. (Abschnitt V) Der letzte Abschnitt VI diskutiert die Folgen einer geschlechtlich codierten Theatralisierung des Opfers.

\section{II.}

Das tragische Ende der Emilia Galotti mag mangelhaft motiviert erscheinen. Diesem Vorwurf soll hier gar nicht widersprochen werden. Umgekehrt kann man sich des Eindrucks nicht erwehren, das Stück verdanke seine außerordentliche Wirkung auch seinen diesbezüglichen Defiziten, oder, vorsichtiger ausgedrückt, seinen kalkulierten Leerstellen. In diese fädeln sich zwei Hauptstränge der Rezeption hinein. Der eine versucht, wie angedeutet, die Verstörung ästhetisch, nämlich dramaturgisch bzw. gattungspoetologisch zu erklären, zu harmonisieren oder zu kritisieren. Da Lessing das dramatische Geschehen tendenziell in Psychologie auflöst, ${ }^{14}$ die Charaktere weniger aus den Handlungen ${ }^{15}$ als vielmehr die Handlungen aus den Charakteren motiviert, lag schon hier der Übergang zum zweiten Hauptstrang nahe, nämlich figuren- und charakterpsychologisch vorzugehen. Flugs verschob sich der Fokus von der Darstellung aufs Dargestellte. Hier nun hinterfragte man weniger, wie stimmig die Konstruktion der Katastrophe ausfalle, sondern wer schuld an ihr sei.

Dergestalt verlagerte sich das Interesse, und zwar in Folge der Kanonisierung Lessings. Diese war spätestens um die Mitte des 19. Jahrhunderts vollzogen. In den Lehrplänen der humanistischen Gymnasien instituiert, bildete er jetzt eine Säule im kulturellen Gedächtnis. Allerdings unterschied sich die frühe Rezeption der Emi-

\footnotetext{
14 Jürgen Fohrmann, »Die Tragödie der Empfindsamkeit und die Rettung der Souveränität«, in: Klaus Garber, Ute Széll (Hrsg.), Das Projekt Empfindsamkeit und der Ursprung der Moderne. Richard Alewyns Sentimentalismusforschungen und ihr epochaler Kontext, München 2005, 115-128, hier: 119.

15 Aristoteles begriff die Tragödie noch explizit als Nachahmung von Handlungen ( $\pi \rho \alpha \xi \varepsilon o v)$ und Lebenswirklichkeiten ( $\beta\llcorner\mathrm{ov})$, nicht etwa als Nachahmung von Menschen. Aristoteles, Poetik $\S 6,1450$ a, übersetzt und hrsg. Manfred Fuhrmann, Stuttgart 1982, 21.
} 
lia im Deutschunterricht ${ }^{16}$ zunächst deutlich von der heute meist gepflegten, in der die Grenzen zwischen Ästhetik, Poetik und Hermeneutik einerseits und Moraldidaktik andererseits zugunsten Letzterer verschwimmen. Weil das Stück »die Geburt der modernen deutschen Tragödie « bedeute, so Kuno Fischer $1881^{17}$, ging es damals noch vornehmlich darum, die Stimmigkeit seiner Dramaturgie nachzuweisen, gegen die zahlreichen Anfechtungen »die Nothwendigkeit und Natürlichkeit der Katastrophe ${ }^{18} \mathrm{zu}$ behaupten. Ein derart kanonisches Werk musste doch stimmig konstruiert sein, auch wenn noch 1929 die Stimme eines Hugo von Hofmannsthal den Chor einer langen kontrapunktischen Tradition verstärkte, die dem »Schluß mit dem Virginiamotiv etwas Überhastetes und Künstliches « attestiert hatte. ${ }^{19}$

Zum kulturellen Monument geworden, hatte sich das Drama ein Prestige erworben, das seine Autorität als Dokument beförderte. Daher konnte die tragende Säule kaum hundert Jahre später von zahlreichen sozialgeschichtlichen Interpretationen kritisch umrankt und gegen bürgerliche Werte in Stellung gebracht werden. In der Debatte, ob es Lessing um ästhetische oder um politische Ziele zu tun war, hatte man sich entschieden. Vermochte sich die erste Position noch auf den Brief an Karl Lessing zu berufen, in dem der Dramatiker zugab, »doch es sei auch mit dem allen, wie es wolle; wenn das Stück nur im Ganzen Wirkung hervorbringt «, ${ }^{20}$ war eine andere, regelmäßig angeführte Selbstaussage auch gegen den Strich, nämlich im Sinne einer sozialpolitischen Agenda lesbar. 1758, 14 Jahre also vor der Uraufführung, teilt Lessing Nicolai mit, er plane eine von allem Staatsinteresse abgesonderte »bürgerliche Virginia«. Dergleichen Absichten, ins Politische zu wirken, schließt er vielleicht nur vordergründig aus. Höfische Verstellungskunst ist vielleicht nicht nur Gegenstand des Stücks. Indem er das »Schicksal einer Tochter, die von ihrem Vater umgebracht ist, dem ihre Tugend werther ist, als ihr Leben, für sich schon tragisch genug « befindet, geht es Lessing eingestanden darum, »die ganze Seele [des Zuschauers] zu erschüttern, wenn auch gleich kein Umsturz der ganzen Staatsverfassung darauf folgte $\ll .{ }^{21}$ Nicht nur, dass die Negation das Negierte überhaupt erst als Möglichkeit ins Spiel bringt, nicht nur, dass die politische Wirkung, keine geringere als ein ganzer Umsturz, nur für den unmittelbaren Horizont ausgeschlossen wird. Indem er das Staatsinteresse dem Bürgerlichen unterordnet, stellt Lessing darüber hinaus Moral über Politik. Demgemäß brächte er das Opfer der Titelfigur als einen »Triumph « auf die Bühne, der »die illegitime politische Macht zugunsten der moralischen Macht aushebe[ln] « soll. ${ }^{22}$

\footnotetext{
16 Vgl. ausführlich Carsten Gansel, Birka Siwczyk (Hrsg.), Gotthold Ephraim Lessings >Emilia Galotti< im Kulturraum Schule (1830-1914), Göttingen 2015, 28 und passim.

17 Kuno Fischer, Lessing als Reformator der deutschen Literatur, 186. Zit. n. Gansel, Siwczyk (Anm. 16), 28.

18 Friedrich Theodor Nölting, Ueber Lessings Emilia Galotti (1878), zit. n. Gansel, Siwczyk (Anm. 16), 107.

19 Hugo von Hofmannsthal, »Gotthold Ephraim Lessing. Zum 22. Januar 1929«, in: Ders., Gesammelte Werke in zehn Einzelbänden, hrsg. Bernd Schoeller, Reden und Aufsätze III, 138-142, hier: $139 \mathrm{f}$.

20 Brief vom 10. Februar 1772, Lessing (Anm. 8), 352.

21 Lessing an Nicolai, 21.1.1758, in: Lessing (Anm. 8), XI/1, 267. Hv. U. St.

22 Claudia Nitschke, Der öffentliche Vater. Konzeptionen paternaler Souveränität in der deutschen Literatur (1755-1921), Berlin 2012, 87.
} 
In der Rezeption der Emilia lässt sich also von Beginn an eine Haupttendenz erkennen: Die dramaturgische Frage nach der Motivierung bzw. die dramenpoetologische nach der Tragödienkonzeption schlägt um in eine nach der Verantwortlichkeit und der Moral handelnder Personen. ${ }^{23}$ An dieser Stelle wird es interessant. Hier fragt sich nämlich, welche der Figuren für das tragische Ende in Haftung genommen wurde. Wie kam es, dass man Odoardo Galotti zum Hauptangeklagten erklärte? Warum nicht die eigentlichen Antagonisten, den intriganten Höfling Marinelli, oder den empfindsam angekränkelten Libertin, den Prinzen? Und hätte man nicht auch Schuldanteile aufs Konto der Titelfigur buchen können? Das hätte ja die vieldeutige aristotelische Kategorie der Hamartia nahegelegt, die der Briefwechsel über das Trauerspiel ausführlich diskutiert. Hingegen umgeht die Hamburgische Dramaturgie, meinte Max Kommerell, auf auffällige Weise eine Diskussion des tragischen Makels. ${ }^{24}$ Zumindest wäre Lessings Haltung dort diskutierbar. Heißt es einerseits, das »Mitleid « verlange laut Aristoteles »einen, der unverdient leidet ${ }^{25}$, bezeichnet Lessing bald darauf den »Gedanke an und für sich selbst [als] gräßlich, daß es Menschen geben kann, die ohne alle ihr Verschulden unglücklich sind «. ${ }^{26}$ Wie aber steht es dann um die Emilia? Ist sie, der »unschuldi[ge] Gegenstand des Verbrechens« (II/6, 316), wirklich »unschuldig, in allem unschuldig« (IV/8, 356) $?^{27}$ Dass ihr Charakter stimmig konstruiert sei, das wurde denn auch oft bezweifelt. Insbesondere von

\footnotetext{
23 Das ähnelt den »diskursiv[en] Strategien« von Boulevardzeitungen, die »die Konstruktion von übersichtlichen Weltbildern und die Reduktion komplexer Vorgänge auf das Handeln einzelner Personen, die dann der moralischen Bewertung [...] unterliegen«, betreiben. So Peter A. Bruck und Günther Stocker, Die ganz normale Vielfältigkeit des Lesens. Zur Rezeption von Boulevardzeitungen, 2. Aufl., Münster u.a. 2002, 29. Brigitte Prutti (Anm. 1), 2, formuliert die überzeugende These, der Stein des Anstoßes bestehe exakt darin, dass der Tod Emilias völlig kontingent erfolge. Dann aber bemüht sie sich, die Kontingenz zu beseitigen, indem sie in einer psychoanalytischen Lektüre Vater und Tochter einen beiderseitigen Inzestwunsch unterstellt.
}

24 Max Kommerell, Lessing und Aristoteles. Untersuchung über die Theorie der Tragödie (1940), 5. Aufl., Tübingen 1984, 122. Im Briefwechsel hatte Lessing der hamartia noch die Funktion zuerkannt, den Charakter glaubhaft zu machen: »Weil ohne den Fehler, der das Unglück über ihn zieht, sein Charakter und sein Unglück kein Ganzes ausmachen würden, weil das eine nicht in dem andern gegründet wäre «. So der Brief an Mendelssohn vom 18. Dezember 1756, Gotthold Ephraim Lessing, Werke, hrsg. Herbert Göpfert, München 1973, IV, 192. Mönch ([Anm. 5], 151ff.) versucht hingegen, eine spezifische »Hamartia-Variante « in der Emilia nachzuweisen. (151ff.) Das ist deshalb schwierig, weil die Zeichnung der Figur als Unschuld so auffällig mit Lessings poetologischem Verdikt über die »unschuldige Tugend « kontrastiert. So Mönch, 42.

25 Hamburgische Dramaturgie, 74. Stück, Lessing (Anm. 24), IV, 575. Vgl. Mönch (Anm. 5), 42.

26 Hamburgische Dramaturgie, 82. Stück, Lessing (Anm. 24), IV, 613.

27 Bis auf Emilia hätten alle Beteiligten Fehlberechnungen und Fehlhandlungen, somit die tragische Katastrophe zu verantworten, meinte Karl Eibl, »Identitätskrise und Diskurs. Zur thematischen Kontinuität von Lessings Dramatik «, Jahrbuch der deutschen Schillergesellschaft 21 (1977), 138-191, hier: 154f. Vgl. jetzt Friedrich Vollhardt, Gotthold Ephraim Lessing. Epoche und Werk, Göttingen 2018, 286-291: In Emilias »Wunsch zu sterben könnte sich [...] zugleich jene moralische Anfechtung zeigen, der sie gerade zu entkommen sucht: die Verlockung des Sinnlichen« (291).

28 So habe Goethe, Riemer zufolge, ein »proton pseudos«, eine falsche Voraussetzung, moniert. Lessing habe versäumt auszusprechen, dass Emilia den Prinzen liebe. Friedrich Wilhelm Riemer, Mittheilungen über Goethe. Aus mündlichen und schriftlichen, gedruckten und ungedruckten Quellen, II, Berlin 1841, 4. März 1812. 
Dramatikern und Schriftstellern, und zwar in einer Weise, in der sich die Grenzen zwischen Darstellung und Dargestellten noch durchlässig erwiesen. ${ }^{28}$

Noch 1839 schloss sich Friedrich Hebbel den Vorwürfen à la Goethe oder Schlegel an. In Kalkül und Konstruktion, so Hebbel, bekunde sich die unpoetische Natur des Stücks: »[D]er Dichter schulmeistert das Musenroß und treibt es im ganzen freilich, wohin er will, aber im einzelnen immer entweder zu weit oder nicht weit genug. « $^{29}$ Daher seien die »Charaktere zu absichtlich auf ihr endliches Geschick, auf die Katastrophe, berechnet« (280). Das äußere sich vor allem in der Unglaubwürdigkeit einer »Tochter, die um ihren Tod bettelt, wie Tausende ums Leben betteln würden« (281). Der Dramatiker bezog indessen das gesamte Figurenarsenal in seine Kritik ein: So fehlkonzipiert wie Tochter, Prinz und das Restpersonal bis hin zum »tragisch[en] Kutscher« (282) erschien ihm insbesondere die Figur des Odoardo: Er sei »ein Vater, der sich leichter zum Äußersten als zu etwas anderem entschließt« (281).

In dieser Hinsicht unterscheidet sich Hebbels Kritik deutlich von vielen anderen Rezeptionszeugnissen. Unter den frühesten finden sich nicht wenige, die zwar Anstoß an der allzu skizzenhaft ausgeführten Zeichnung der Emilia nahmen. Am Vater aber missfiel ihnen in aller Regel weniger die dramatische Konstruktion des Charakters als dieser selbst.

Eines der aufschlussreichsten dieser frühen Dokumente stammt von Johann Jakob Bodmer. Eine Generation älter als Lessing, publiziert der Pfarrerssohn, Professor für Geschichte, Dichter und Ästhetiker 1778 ein »literaturkritische[s] Metadrama «. ${ }^{30}$ Sechs Jahre nach der Uraufführung kritisiert das Dramolett Odoardo Galotti, Vater der Emilia ${ }^{31}$ Lessings Erfolgsstück aufs deutlichste, und zwar in Gestalt eines dramatischen Epilogs: Das Nachspiel mit parodistischen Elementen setzt nach der Dramenhandlung ein, indem es den nach der unerhörten Tat heimkehrenden Vater mit der Reaktion zuhause konfrontiert. Das »Pendant zu Emilia«, so der Untertitel, nimmt dabei eine Konstante der Rezeptionsgeschichte vorweg. Während Bodmer an der Figur der Emilia die Konstruktion des Charakters kritisiert, hält auch er, so scheint es, denjenigen des Odoardo für glaubhaft. Folglich greift er die Figur selbst an.

Zunächst habe Lessing, so Bodmer, weder den Charakter der Titelfigur stimmig gezeichnet noch die tragische Katastrophe glaubhaft motiviert. Um das einsichtig zu machen, greift der von den neueren dramatischen Tendenzen ersichtlich befrem-

\footnotetext{
${ }^{29}$ Friedrich Hebbel, Tagebücher, in: Ders., Werke in fünf Bänden, hrsg. Gerhard Fricke, Werner Keller, Karl Pörnbacher, IV, München 1966, 279. Nachweise im Folgenden unter einfacher Nennung der Seitenzahl im Text.

${ }^{30}$ Dirk Niefanger, »Nicht nur Dokumente der Lessing-Rezeption. Bodmers literaturkritische Metadramen >Polytimet< und >Odoardo Galotti««, in: Anett Lütteken (Hrsg.), Bodmer und Breitinger im Netzwerk der europäischen Aufklärung, Göttingen 2009, 410-428. Unter »Metadrama« versteht Niefanger ein Stück, in dem »bewusst eigene und kritisierte Schauspielformen auf der Bühne öffentlich und kontrastiv verhandelt werden. Theaterkritik geschieht hier also ausdrücklich im Modus des Theatralischen«. (420) Darin grenze sich das Stück von bloß parodistischen oder satirischen Verfahren ab, von denen es gleichwohl nicht frei sei. (416f).

${ }^{31}$ Odoardo Galotti, Vater der Emilia. Ein Pendant zu Emilia. In einem Aufzuge und Epilogus zur Emilia Galotti. Von einem längst bekannten Verfasser, Augsburg 1778. Zitate werden im Folgenden direkt im Text belegt.
} 
dete Ältere zu einem Mittel, das späteren Lesern höchst avanciert, gleichsam wie ein Verfremdungseffekt anmuten könnte: Als Metadrama durchbricht das Stück die theatralische Illusion, es endet nämlich in einem Epilogus, einem Nachspiel sozusagen zum Nachspiel, in dem die Schauspielerin der Emilia ihr Kostüm ablegt und sich durch die vierte Wand hindurch ad spectatores wendet: Die »Unvollkommenheit in [ihrer] Aufführung « möchte man bitte nicht ihr, der Darstellerin, sondern allein den Unstimmigkeiten der Figur anlasten. Dabei kritisiert sie die Emilia im Namen der empfindsamen Werte: Die Darstellerin selbst »schmeichle « sich, »so zärtlich, so tugendhaft, so ruhig, und dabey so entschlossen« zu sein »als die Emilia, des alten Degens Odoardo Tochter«; aber deren Empfindungen widersprächen denen der Darstellerin ganz entschieden: Weder hätte sie sich vom Verlobten und der Mutter fortreißen lassen, noch sich von der Furcht vor dem Verführer in den »Selbstmord « treiben lassen. Dazu sei sie zu »christlich« $(28 \mathrm{f})$. Vor allem aber erklingt aus dem Mund der Schauspielerin die Kritik des Autors an einem Vater, der dem Modell des empfindsamen Vaters in keiner Weise mehr genügt. Odoardo habe nämlich »den Vater über dem sclavischen Unterthanen« vergessen und im Stolz über die Versicherung der Tochter, sie könne für ihre Sinnlichkeit nicht einstehen, zugestoßen und »die Unschuldige [...] ermord[et]« (30). Den »Mord der beßten Tochter « (25) gesteht der am Ende zerknirschte Vater selbst ein. Seine Untat übertrifft noch die des Prinzen, der sich am Ende zu seiner Schuld bekennt und sich bezichtigt, ein korrupter Lüstling gewesen zu sein. ${ }^{32}$

Odoardo Galotti, das ist »der unnatürliche Vater« (30), so resümiert die Schauspielerin, was das Metadrama schon in seinem ersten Teil in aller Ausführlichkeit hatte vorführen wollen. Ernste poetologische und moralische Absichten verfolgend, ${ }^{33}$ setzt Bodmer nachdrücklich den Vater als den Hauptschuldigen an der Tragödie in Szene. Neben der seinen droht die Schuld des Prinzen beinah zu verblassen. Bodmer ist es klar darum zu tun, den Vater als einen Familientyrannen zu denunzieren, der, anstatt seine Affekte zu beherrschen, sich von ihnen beherrschen lässt. ${ }^{34}$

Odoardo Galotti ist kein zärtlicher Vater. ${ }^{35}$ So lautet der Vorwurf Bodmers im Kern, und darin befindet er sich durchaus im Einklang mit anderen zeitgenössischen Rezeptionsdokumenten. Er wiederholt ihn in einer der zahlreichen Paraphrasen Lessings, mit denen Bodmer seinen Gegenstand systematisch konterkariert. Wenn der Odoardo des Metadramas im falschen Tugendstolz schwelgend meint, »lieber« wolle er »keine Tochter, als ein Kebsweib erzeuget haben« (12), dann verkehrt er einen Satz ins Gegenteil, mit dem noch Sir William Sampson gleich im ersten Auftritt der Sara seine empfindsamen Vorzüge herausstreichen durfte: »Ich würde doch lieber von einer lasterhaften Tochter, als von keiner, geliebt sein wollen.« ${ }^{36}$

\footnotetext{
32 Vgl. auch Nitschke (Anm. 22), 86 f.

33 Niefanger (Anm. 30), 416.

34 Vgl. Niefanger (Anm. 30), 419.

35 Vgl. Sørensen (Anm. 6). Reiner Wild, Die Vernunft der Väter. Zur Psychographie von Bürgerlichkeit und Aufklärung in Deutschland, Stuttgart 1987.

36 Auf diese Parallele zu Lessing, Miß Sara Sampson I/1, in: Ders., Werke (Anm. 24), II, 12, weist Nitschke (Anm. 22), 86f. hin.
} 
Odoardo sei nicht nur kein zärtlicher Vater, sondern, in seiner Autoritätshörigkeit, ein Fürstenknecht. Als wollte er Freytags Einwand vorwegnehmen, warum der Vater nicht den Verführer erdolcht habe, lässt Bodmer ihn sagen: »Die Person des Prinzen ist mir heilig; ich fluche der Hand, die sich an dem Souverain des Gesetzes vergreift«. Das hält Odoardo Appiani entgegen. Der hatte in der Kontrafaktur das Attentat nämlich überlebt, um Odoardo nun vorzuwerfen, er habe sich dem »Wohllüstling « nicht entgegengestellt (17). Und es gibt einen weiteren Vorwurf, den schon der Schweizer Lessing-Skeptiker ventiliert und den man später immer wieder erhoben hat. Jeder, so sinniert Bodmers Odoardo, der »die ächten Begriffe von Ehre hat «, müsse seiner Tat doch zustimmen (12). Im Namen der Ehre, so der Tenor der Anklage, opfere der Vater die Tochter, weil er deren Tugend mit ihrer Jungfräulichkeit verloren wähnt. Gegen diesen unterstellten Tugendrigorismus wendet die Darstellerin der Emilia ein, »die Unschuld wäre durch die gewaltthätigste Mishandlung meiner Person nicht wirklich verlohren gegangen« (30).

Es ist leicht zu sehen, dass Bodmer hier eine Pointe Lessings nicht erkannt hat. Von der Ehre, zumal von einer in der Virginität der Tochter symbolisierten, denkt Lessings Odoardo nämlich längst nicht so hoch, wie ihm die Kontrafaktur und eine lange Deutungstradition unterstellen. Gegen diese Auffassung argumentierte schon Friedrich Nicolai, als er das Stück vor den Teilen des Publikums in Schutz nahm, die irrig wähnten, »daß der Vater seine geliebte Tochter bloß aus Besorgnis der Verführung « erstochen hatte. ${ }^{37}$ Am deutlichsten wurde das Missverständnis, Odoardo töte, ja »ermord[e]« seine Tochter aus Sorge um ihre physische Jungfräulichkeit, wohl von Ludwig Börne artikuliert. Der hatte »sich mit Abscheu vor einem solchen Anblicke « und vor allem von einem Vater abgewandt, der »seine Tochter ermordet [...] nur um ihre anatomische Unschuld zu retten «.38

Dabei lässt das Stück eigentlich keinen Zweifel daran, dass es nicht die Sorge um die Jungfräulichkeit ist, die die Tötung der Tochter motiviert. Schließlich versichert Odoardo deutlich, ihre Unschuld sei »über alle Gewalt erhaben« (V/7, 369). ${ }^{39} \mathrm{Er}$ pocht gerade nicht auf die Ehre, schon gar nicht auf die Familienehre. Er beruft sich vielmehr auf eine Würde, derer Emilia auch im Falle einer Vergewaltigung nicht verlustig ginge. Ehre dagegen ist eingestanden ein »soziales Konstrukt«, wie man heute sagen würde. Sie existiert nur, insofern sie in den Augen der anderen existiert. Ehre bedarf darum stets der Behauptung, und zwar im doppelten Sinne: Als Statement und Prätention einerseits, und im Kampf gegen jede auch nur unterstellte Anfechtung, Verletzung, Beleidigung oder Missachtung andererseits. Würde aber ist als ein naturrechtlich Gegebenes unauflöslich mit der Person verknüpft. ${ }^{40} \mathrm{Nicht}$ zuletzt darum konnte der Begriff zur Säule eines bürgerlichen Selbstbewusstseins

\footnotetext{
${ }^{37}$ Brief an Lessing vom 7. April 1772, Lessing (Anm. 8), XI/2, 389; Hv. i. O.

${ }^{38}$ Ludwig Börne, »Emilia Galotti. Von Lessing«, in: Ders., Sämtliche Schriften, hrsg. Inge u. Peter Rippmann, 3 Bde., I, Düsseldorf 1964, 366-372, hier: 366.

${ }^{39}$ Es handelt sich hier um eine apodiktische Feststellung und nicht etwa um eine »rhetorisch gemeinte Frage«, wie Alexander Košenina, Literarische Anthropologie. Die Neuentdeckung des Menschen, Berlin 2008, 166, gegen den Wortlaut behauptet.

${ }^{40}$ Hier wären Luther, Pufendorf oder Kant als maßgebliche Positionen zu nennen. Vgl. Andreas Grossmann, »Würde «, in: Joachim Ritter, Karlfried Gründer, Gottfried Gabriel (Hrsg.), Historisches Wörterbuch der Philosophie, XII, Basel 2004, Sp. 1088.
} 
avancieren. Anders als Bodmer ihm unterstellt, glaubt Lessings Odoardo längst nicht mehr an die Ehre. Nicht anders als zuvor Appiani begreift er die ständische Gebundenheit und zumal den Scheincharakter des Konzepts und wehrt die mit ihrem Einsatz verbundenen Handlungszumutungen höhnisch $\mathrm{ab}: » \mathrm{O}$ des gnädigen Prinzen! O der ganz besondern Ehre!« (IV/7, 355)

Dieser Punkt kann in seiner Wichtigkeit kaum überschätzt werden. Bekanntlich gehen Lessings Pläne, den Virginia-Stoff zu adaptieren, bis auf das Jahr 1754 zurück. 1757/58, der Briefwechsel mit Nicolai dokumentiert es, haben sich diese zum Vorhaben einer bürgerlichen Virginia, zur Emilia Galotti konkretisiert. In der Zwischenzeit, 1756, war Johann Gottlob Benjamin Pfeils Lucie Woodvil aufgeführt und gedruckt worden. Anders als die ein Jahr ältere Miß Sara Sampson führt Pfeils Stück die Gattungsbezeichnung »bürgerliches Trauerspiel« im Untertitel explizit an und begibt sich darin gleichsam in Konkurrenz zu Lessings Bestrebungen. In der Lucie war die Jungfräulichkeit noch die »Ehre«, die die Titelheldin dem Verführer Karl Southwell, von beiden ungewusst ihr Bruder, »aufgeopfert « hatte. ${ }^{41}$

Im dramatischen Konflikt der Emilia zeichnet sich damit markant eine mentalitätsgeschichtliche Zäsur ab. Im Anliegen, das adlige Konzept der Ehre zu diskreditieren und gegen sie das Prinzip der Würde ins Feld zu führen, ${ }^{42}$ tritt eine neue moralische Kultur historisch mächtig auf den Plan. Wenn an die Stelle der Reputation die Würde tritt, das beschreiben die amerikanischen Soziologen Bradley Campbell und Jason Manning, greife man im Falle ihrer Anfechtung nicht mehr zur Waffe. Anstatt kühn, empfindlich oder aggressiv zu agieren, übe man die Tugenden der Zurückhaltung, Umsicht und Selbstsicherheit. Im Konfliktfall wendet man sich an die legitimen Autoritäten. ${ }^{43}$ Wenn sich Odoardo den Behörden und damit dem irdischen Gericht stellt, beschränkt er sich nicht darauf, seine Tugend nur als »moralische Gesinnung im Kampfe $\ll^{44}$ einzusetzen. Er verharrt nicht tugendempfindsam in der Ausstellung von Gesinnung, er handelt vielmehr einschlägig, indem er sich stellt.

Bodmers Kritik hatte jedoch Schule gemacht. Indem man Odoardo unterstellt, er opfere seine Tochter, um ihre, seine oder die Ehre der Familie zu verteidigen, lässt sich die hergebrachte Kritik der höfischen Gesellschaft passgenau auf die bürgerliche übertragen. Und die Geschichte dieser Übertragung fällt zusammen mit der Geschichte des bürgerlichen Trauerspiels. Ist es doch diese Gattung, die die tradierten Motive der Hofkritik ${ }^{45}$ bündelt und so ein semantisches Arsenal versammelt, mit dem bald die Kritik an der modernen Gesellschaft operieren kann. ${ }^{46}$ In

\footnotetext{
41 Lucie Woodvil, ein bürgerliches Trauerspiel in fünf Aufzügen, Leipzig 1786, 15.

42 Vgl. auch Achim Geisenhanslüke, Die Sprache der Infamie II: Literatur und Niedertracht, München 2018, 31 ff. über Schiller, die Ehre und die Krise der Tragödie; 59 über Lessing und die Zurückdrängung des Ehrbegriffs, allerdings nur in der Komödie.

43 Vgl. Bradley Campbell, Jason Manning: The Rise of Victimhood Culture. Microaggressions, Safe Spaces, and the New Culture Wars, Palgrave McMillan (o.O.) 2018.

44 Immanuel Kant, Kritik der praktischen Vernunft, hrsg. Joachim Kopper, Stuttgart 1989, 137. Hv. U. St.

45 Vgl. Helmuth Kiesel, »Bei Hof, bei Höll«. Untersuchungen zur literarischen Hofkritik von Sebastian Brant bis Friedrich Schiller, Tübingen 1979.

46 Noch heute wird eine Kontinuität zwischen dem bürgerlichen Trauerspiel und dem sozialen Drama, nämlich ein gemeinsames »zentrales Anliegen« unterstellt: »das Anliegen, die durch gesellschaftliche Entwicklungen benachteiligten, von politischen wie wirtschaftlichen Ressourcen ausgeschlossenen Bevölke-
} 
dem Moment, in dem ihr eigentlicher Gegenstand, der Hof, an Bedeutung zu verlieren begann, konnte sich die Hofkritik als Matrix einer Kritik an der bürgerlichen Gesellschaft etablieren.

Es bleibt also festzuhalten: Odoardo tötet Emilia nicht um der Ehre willen, nicht aus Sorge um eine mit ihrer Jungfräulichkeit verbundenen Familienehre. Er begeht keinen Ehrenmord. ${ }^{47}$ Wenn aber die Tochter trotz oder auch gerade wegen der drohenden Verführung ihre Würde behält, stellt sich dann nicht die zentrale Frage, warum er sie tötet, umso dringlicher? Die nächstliegende Antwort wird in der Regel vergessen: Weil seine Tochter es so will. Zwar füllt er die Rolle des zärtlichen Vaters nur unzureichend aus. Und dennoch ist Odoardo ein solcher Vater, der, um eine Formulierung aus Carl Friedrich Großmanns in Teilen an Lessing angelehntes Erfolgslustspiel Nicht mehr als sechs Schüsseln auf ihn zu münzen, »seinem lieben Töchterchen nichts abschlägt ${ }^{48}$ Noch nicht einmal ihr Ansinnen, sie zu töten. Daher müsste man die Frage, wie sie meist formuliert wird, eigentlich anders stellen. Es fragt sich womöglich weniger, warum der Vater seine Tochter tötet, als vielmehr, warum sie sich töten lassen will.

Wenn man das Rätsel, warum eine Figur um den Tod bettelt wie sonst andere um ihr Leben, charakterpsychologisch angeht, kommt man, wie Hebbel, kaum umhin, dem Autor anzukreiden, er habe unzureichend motiviert. Vertritt man hingegen die Position, Lessing habe schlüssig konstruiert, muss man bestreiten, die Lösung finde sich, indem man sich »in das Gefühlsleben der dargestellten Person « einfühlt. ${ }^{49}$ Gisbert Ter-Nedden hat recht, wenn er die charakterpsychologische Lösung zurückweist. Stattdessen meint er, Lessing verkehre den Masterplot der Jungfrau, die vor männlicher Gewalt in den Tod flüchte, in sein Gegenteil. Anstatt die »konventionell[e] Tugendprobe [...] in moderner Kostümierung « $\mathrm{zu}$ wiederholen, erfahre die verfolgte Unschuld selbst einen Sündenfall. ${ }^{50}$ Sie flüchte »nicht vor der männlichen

rungsschichten tragikfähig zu machen«. So Franziska Schößler, Einführung in das bürgerliche Trauerspiel und das soziale Drama, Darmstadt 2003, 7.

47 Dieser Vorwurf ist jüngst noch einmal laut geworden: Odoardo begehe seine Tat im Geiste des römischen pater familias und dessen Privileg, die männliche und die Ehre der Familie durch einen Ehrenmord zu behaupten. So Dorothea von Mücke, »Emilias Andacht und Gretchens Gewissen. Goethes Auseinandersetzung mit Lessing in der Arbeit an der Faust-Tragödie«, Jahrbuch der deutschen Schillergesellschaft (2019), 165-195, hier: 178. Dem römischen Hausvater mochte das Recht über Leben und Tod noch zugestanden haben. Seit der frühen Neuzeit ist das definitiv nicht mehr der Fall. Die Position des Patriarchen wurde vielmehr einer immer stärkeren Verrechtlichung unterzogen, die u.a. die Einklagbarkeit seiner Pflichten garantierte. Vgl. Heinrich R. Schmidt, »Hausväter vor Gericht. Patriarchalismus als zweischneidiges Schwert«, in: Martin Dinges (Hrsg.), Hausväter, Priester, Kastraten: zur Konstruktion von Männlichkeit in Spätmittelalter und früher Neuzeit, Göttingen 1998, 213-236 sowie Steiner, »Die Entsorgung des Hausvaters« (Anm. 3), $147 \mathrm{f}$.

48 Gustav Wilhelm Friedrich Großmann, Nicht mehr als sechs Schüsseln. Ein Familiengemälde in fünf Aufzügen, o.O. 1781, 45. Großmann verstand sich als Propagator und Popularisierer von Lessings Dramaturgie. Sein Erfolgsstück legt denn auch ein klares Bekenntnis zur Würde ab und spielt sie explizit gegen das adlige Konzept der Ehre aus. Vgl. Steiner, »Die Entsorgung des Hausvaters« (Anm. 3), $151 \mathrm{f}$.

49 Gisbert Ter-Nedden, »Lessings dramatisierte Religionsphilosophie. Ein philologischer Kommentar zu Emilia Galotti und Nathan der Weise«, in: Christoph Bultmann, Friedrich Vollhardt (Hrsg.), Lessings Religionsphilosophie im Kontext. Hamburger Fragmente und Wolfenbütteler Axiomata, Berlin, New York 2011, 283-336, hier: 289.

50 Ter-Nedden (Anm. 49), 292. 
Gewalt, sondern in religiös begründeter Sündenfurcht vor der eigenen weiblichen Sexualität in den Tod . $^{51}$

Damit glaubt Ter-Nedden einen weiteren Vorwurf hinsichtlich der tragischen Lösung abgewehrt $\mathrm{zu}$ haben, nämlich den, Lessing widerspreche sich selbst, er widerspreche seiner Ablehnung der Märtyrertragödie in der Hamburgischen Dramaturgie. ${ }^{52}$ Vielmehr formuliere Lessing hier sozusagen Theologiekritik in dramatischer Gestalt, indem er Emilias Identifikation mit dem Märtyrertum ${ }^{53}$ frag- $^{-}$ würdig und fadenscheinig erscheinen lasse. Auch in der Darstellung Emilias mache sich der »Lessing-Code « geltend, demzufolge zwischen der Erlebnisperspektive der Figuren und einer höhergelagerten kognitiven Ebene eine Dissonanz erklinge und dergestalt Kritik motiviere. Die Tragödie sei gerade nicht zwangsläufig, sondern unnötig! Es gebe keinen »vernünftigen Grund« für den Tod Emilias, meint TerNedden.

Ter-Nedden erkennt also die mangelhafte Motivation des tragischen Schlusses. Noch diese sei als ästhetisches Kalkül Lessings zu begreifen, der gerade zeigen wolle, wie unnötig das Ende sei, für das die egoistischen Verblendungen aller mit Ausnahme der Titelfigur Beteiligten verantwortlich zeichneten. Insbesondere die des Vaters. ${ }^{54}$ So sehr glaubt der Interpret an die Souveränität des Autors, dass er den Vorwurf mangelnder Motivierung in eine Auszeichnung ummünzt. Nirgendwo vollzieht sich daher die Verlagerung von der dramenpoetologischen Frage nach der Stimmigkeit der Konstruktion auf die Verantwortlichkeit und Moral der handelnden Personen dezidierter und klarer als in dieser exemplarischen Deutung. Emilias Eifer, in den Tod zu gehen, sei quasi das Produkt einer fehlgeleiteten religiös-moralischen Erziehung. Sie sei »nicht nur ein frommes und gehorsames Opfer, sondern ein Opfer ihrer Frömmigkeit und ihres Gehorsams «, ${ }^{55}$ ein Opfer mithin einer falschen, vom Vater repräsentierten Moral. In dieser Sicht zeichnet auf einmal nicht mehr der Widerstreit zwischen Hof und Familie für den tragischen Konflikt verantwortlich, nicht mehr der Antagonismus zwischen höfischer Öffentlichkeit und empfindsamer Familie, sondern Letztere selbst. ${ }^{56}$ Nicht die vom Hofe ausgehende Verführung, von der Emilia spricht, sondern die familiale Liebe sei die wahre Gewalt, hieß es des Öfteren. ${ }^{57}$

51 Ter-Nedden (Anm. 49), 289.

52 Ter-Nedden (Anm. 49), 292.

53 Vgl. zur Märtyrerproblematik Sigrid Weigel, »Emilia Galotti - Opfer, Säkularisierung und tragisches Subjekt «, in: Dies. (Hrsg.), Märtyrer-Porträts. Von Opfertod, Blutzeugen und heiligen Kriegern, München 2007, 59-62.

54 Gisbert Ter-Nedden, Lessings Trauerspiele. Der Ursprung des modernen Dramas aus dem Geist der Kritik, Stuttgart 1986, 229.

55 Ter-Nedden (Anm. 54), 234.

56 Gerd Hillen, »Die Halsstarrigkeit der Tugend. Bemerkungen zu Lessings Trauerspielen«, Lessing Yearbook 2 (1970), 115-134, hat schon 1970 die These vertreten, Emilia sei das Opfer einer sinnenfeindlichen familiären Erziehung. Der Anteil des Hofes an ihrem Schicksal verblasst in dieser deutlich vom damaligen Zeitgeist beflügelten Deutung. Im selben Jahr hatte Fritz Kortner das Stück in Wien inszeniert. Es handle, laut Kortner, nicht etwa von der Macht des Adels, sondern von der »institutionalisierte[n] Repression« durch die Familie und ihren Tyrannen Odoardo. Die Schuld liege nicht bei dem, der das »Bürgermädchen [sic!] >geschändet< hat, sondern bei denen, die es für >geschändet< halten «. In dieser Inszenierung »gegen den Strich« (Zitate nach Grimm [Anm. 7], 180) wurde die Bürstrichtung wohl auch durch das Wehen eines Zeitgeistes befördert, der die »Ablösung der Selbstdisziplinierungswerte durch die Selbstentfaltungswerte« 
Ter-Nedden meint denn auch, die »konventionelle Hofkritik« diene Lessing nur als »Lieferant jener Blindheiten und Vorurteile«, gegen die sein Aufklärungsunterfangen angehe. ${ }^{58}$ Bodmers Urteil über den »unnatürlichen Vater « (s.o.) kehrt in TerNeddens Verdikt wieder, Odoardo sei Lessings »Anti-Vater « schlechthin. ${ }^{59}$ Er begehe »das schlimmste Verbrechen, die Ermordung des eigenen Kindes«, und gebe dies noch als »Tugendprobe « aus. ${ }^{60}$

An Stelle des Prinzen muss nun also der Vater den Kopf hinhalten, dessen Tugend- und Moralvorstellungen die Tochter in den Tod getrieben hätten. Und nicht nur der Vater, sondern, fast stärker noch, der Mann. Man dürfe, so Ter-Nedden, »die männlich-egozentrischen Züge [...] nicht überhören«, die Lessing seiner Figur verliehen habe. Ja, Odoardo sei ein »gestörtes Verhältnis zur Natur« zu attestieren, das »mit seiner Männlichkeit zusammen[hängt] «. ${ }^{61}$ Nicht nur als Vater, der »sich in den Rechten der väterlichen Verfügungsgewalt verletzt« wähne und keine Spur einer »Sorge um das Kind « aufweise, ${ }^{62}$ wird Odoardo auf die Anklagebank zitiert und »einer fehlgehenden dirigistischen Moralerziehung $^{63}$ bezichtigt. Sondern auch als Mann. Männer haben ein gestörtes Verhältnis zur Natur, meint der Interpret. Zugleich mit der Kategorie des tragischen Opfers wird jetzt die Frage nach dem Geschlecht akut. Explizit als Mann findet sich Odoardo in einer nicht nur feministisch geprägten Deutungsgeschichte zwar in der Rolle des Sündenbocks wieder, aber eben nicht mehr in der des tragischen Helden.

Ter-Neddens Anklage fällt beeindruckend, ja einschüchternd aus. Sie fasst gleichsam alle in der Deutungsgeschichte gegen Odoardo erhobenen Vorwürfe aufs Elaborierteste zusammen. Und sie wiegt schwer, ist doch der Ankläger einer der größten Lessing-Kenner. Wer wollte nach ihr noch ernsthaft Gerechtigkeit für Odoardo Galotti erwägen? Lässt sich überhaupt etwas gegen sie einwenden? Ja, das lässt sich. Da ist etwa Ter-Neddens Verständnis der Titelfigur. Ihr spricht er jeden eigenen Willen rundweg ab: »Emilia [hat] keinen eigenen Willen. Als gehorsames Kind macht sie sich vielmehr den Willen ihrer Eltern zu eigen $\ll .{ }^{64}$ Wenn sie aber in V/7 den eigenen Willen explizit geltend macht, dann sei das »fragwürdig«, weil Emilia dort »wir« sage, wo bei Odoardo »ich« steht. ${ }^{65}$ Halten wir die Neigung des Interpreten fest, der Figur die Worte im Munde umzudrehen. Wenn es ihm passt, nimmt er sie

betrieb. So Panaiotis Kondylis, Der Niedergang der bürgerlichen Denk- und Lebensform (1991), 3. Aufl., Berlin 2010, 209.

57 Vgl. Karin A. Wurst, Familiale Liebe ist die swahre Gewalt . Die Repräsentation der Familie in G. E. Lessings dramatischem Werk, Amsterdam 1988.

58 Ter-Nedden (Anm. 54), 177.

59 Ter-Nedden (Anm. 54), 190. Zwar habe Bodmer, so Ter-Nedden, 245, Lessing komplett missverstanden. Er adressiere exakt die Vorwürfe an und gegen den Autor, die dieser in Wahrheit gegen seine Figuren richte. Am Inhalt der Vorwürfe aber hat Ter-Nedden wenig auszusetzen.

60 Ter-Nedden (Anm. 54), 172.

61 Ter-Nedden (Anm. 54), 232 und 235.

62 Ter-Nedden (Anm. 54), 232.

63 Peter-André Alt, Aufklärung. Lehrbuch Germanistik, Stuttgart, Weimar 1996, 222.

64 Ter-Nedden (Anm. 54), 233.

65 Ter-Nedden (Anm. 54), 233. Lessing V/7, 368. Allein auf derselben Seite verwendet Emilia das Wort »ich« einschließlich des Reflexivums »mich« insgesamt dreizehnmal. 
aber beim Wort: Emilia selbst behaupte ja von sich: »Ich habe keinen Willen gegen den Ihrigen«. Das sagt sie der Mutter. Kurz zuvor schon hatte sie beteuert, »wie gern [sie] Ihren bessern Einsichten [sich] in allem unterwerfe $(\mathrm{II} / 6 ; 317)$. Kann man den eigenen Willen bestreiten, ohne über ihn zu verfügen? Und vermag die Bekundung, sich zu unterwerfen, nicht auch eine subtile Strategie der Macht darzustellen?

Ein gar nicht mal subtiles, vielmehr drastisches Machtspiel betreibt Emilia zumindest in der entscheidenden Szene V/7. Warum wird der ebenso schlichte wie augenfällige Befund häufig ignoriert, dass sie es ist, sie, die zuvor so blasse und passive Gestalt, die hier die Initiative ergreift und den Vater massivst zu einer Tat drängt, die kein Vater sich wünschen kann zu begehen, zu einer Tat, die ihn schuldig werden lässt? Emilia mag eine passive Gestalt, das Objekt männlichen Begehrens, den Gegenstand von von Männern geführten Reden ${ }^{66}$ und als solche ein Opfer, eine victima, darstellen. Dieser Befund klingt plausibel und trifft wohl auf weite Strecken des Dramas zu. Nicht aber auf die vorletzte Szene! Wie so viele beansprucht auch Ter-Nedden, im Namen des unschuldigen Opfers zu sprechen. Aber warum entmündigt er, und warum entmündigen mit ihm so viele Interpretinnen und Interpreten das Objekt ihrer gutmeinenden - darf man sagen: paternalisierenden? Fürsorge, indem sie ihm Willen, eigenständiges Handeln und Sprechen gerade in dem Moment absprechen, in dem sie sich im Stück am deutlichsten äußern? Ob die Opferadvokaten wirklich immer im Interesse des Opfers sprechen, diese Frage ist kaum zu vermeiden. ${ }^{67}$

Es gibt wohl einen Grund, warum eine ganze Interpretationstradition die in der Kulminationsszene vorgebrachten Sprechakte entweder ignoriert oder gegen den Wortsinn auslegt: Nur so lässt sich nämlich die These halten, Emilia sei ein passives Opfer. Zur Debatte steht mithin die Möglichkeit einer Viktimologie, die ästhetische Befunde mit einer sozialpolitischen Agenda zusammenbringt.

\section{III.}

Emilia ist ein Opfer, gewiss. Oft wird sie auch so genannt. ${ }^{68}$ Interessanterweise aber nicht im Drama selbst. Das frappiert umso mehr, als die Lucie Woodvil ihre tragische Heldin gut zwanzigmal mit dem Wortstamm markiert hatte. ${ }^{69}$ Es spricht viel dafür, dass Lessing die Sache des Opfers dergestalt angeht, dass er sie nicht beim

\footnotetext{
66 Vgl. z.B. Judith Frömmer, »Vom politischen Körper zur Körperpolitik. Männliche Rede und weibliche Keuschheit in Lessings >Emilia Galotti««, DVjs 79 (2005), 169-195. Volker C. Dörr, »>Aber Gift ist nur für uns Weiber; nicht für Männer . Sprache, Macht und Geschlecht in Lessings >Emilia Galotti««, Orbis litterarum 67/4 (2012), 310-331.

67 Vgl. Gayatri Chakravorty Spivak, »Can the Subaltern Speak?«, in: Cary Nelson, Lawrence Grossberg (Hrsg.), Marxism and the Interpretation of Culture, Basingstoke 1988, 271-313. Daniele Giglioli, Die Opferfalle. Wie die Vergangenheit die Zukunft fesselt, Berlin 2016, 10 u.Ö.

68 Brigitte Prutti, Bild und Körper. Weibliche Präsenz und Geschlechterbeziehungen in Lessings Dramen: ¿Emilia Galotti< und >Minna von Barnhelm<, Würzburg 1996, 5, will in der Opferhandlung eine »gewaltsame Verbildlichung der weiblichen Figur« erkennen, ohne dass klar würde, ob diese auf der Ebene des Dargestellten oder der Darstellung zu verorten wäre.

69 Ich greife hier eine Beobachtung von Karsten Asbahr auf.
} 
Wort nennt, sondern ganz der Darstellung anheimgibt: showing, nicht telling. ${ }^{70}$ Zwar kommt das Lexem in der Emilia durchaus vor, insgesamt ganze fünfmal. Im Munde wird es indes einzig vom Prinzen geführt, der sich der anberaumten Konvenienzehe wegen einmal als »Opfer eines elenden Staatsinteresses « wähnt (I/6, 301). Und von Marinelli. Auch er setzt das Empathiegebot, das vom Begriff des Opfers ausgeht, strategisch ein, wenn er seine Bereitschaft, sich »für die Großen aufzuopfern«, betont (III/1, 326). Daneben verweist das Lexem aus seinem Munde einmal auf die Orsina, das andere Mal auf Appiani. Sonst gebraucht keine andere Figur das Wort, auch nicht mit Bezug auf Emilia. Es ist einzig der Hof, es sind, könnte man sagen, die Täter, die sich das von ihm ausgehende Empathiegebot zunutze machen.

Umso häufiger fällt das Wort in der Forschung. »Opfer im konkreten Sinne des Wortes « sind im bürgerlichen Trauerspiel, meinte Inge Stephan, »vor allem die Töchter«, und das trifft soweit ja auch zu. Konkret aber verstand Stephan unter »Opfer« nur die victimae: Die Töchter brächten sich nicht selbst um, wie Mellefont oder Ferdinand, »sie werden umgebracht«. Namentlich »der Kampf Emilias mit dem Vater um den Dolch ist mehr als ein Kampf um die Waffe. Es ist eine Auseinandersetzung, in der der Vater die Tochter in jene passive Rolle des Opfers zurückdrängt, die sie selbst aktiv durchbrechen wollte. Nur als passives Opfer kann die Frau zum Objekt des Austausches und zum Objekt des Kampfes zwischen Männern gemacht werden ${ }^{71}{ }^{71}$ Inwiefern eine tote Emilia noch zum Gegenstand eines Tausches zwischen Männern taugt, und ob sich ferner Kampf und Tausch nicht wechselseitig ausschließen, sei dahingestellt. Eine rein passive Rolle aber nimmt die Titelfigur allein in dieser und in anderen Deutungen ein, die der Tochter eigenständiges Handeln selbst dort absprechen, wo sie vehement aktiv wird.

Schon Lessing selbst hatte auf des Bruders Karl Kritik ${ }^{72}$ am allzu frommen und gehorsamen Charakter der Emilia reagiert und einen deutlichen Fingerzeig gegeben: »Am Ende wird denn auch freilich der Charakter der Emilia interessanter, und sie selbst tätiger. $\ll^{73}$ Stephan übersieht das. Auch sie reduziert die Figur der Emilia auf eine Passivität, von der am Ende gar keine Rede mehr sein kann. Sie unterschlägt zudem die maßgebliche Bedeutungskomponente des sacrificium, des Opfers als kultischer, ritueller Handlung. Und sie ignoriert die Verbindung zwischen dem kultischen Opfer und der Position des tragischen Helden.

Seit Langem ist über die Geburt der Tragödie aus dem Geist des Opferrituals spekuliert worden. »Die tragische Dichtung «, schreibt Walter Benjamin, »ruht auf der Opferidee « ${ }^{74}$ Benjamins These geht womöglich auf Goethe zurück, der einen ähnlichen Gedanken genau hundert Jahre zuvor, nämlich 1827, formuliert hatte:

\footnotetext{
70 Die narratologische Unterscheidung zwischen »showing « und »telling « geht auf Percy Lubbock zurück. Vgl. Matías Martínez, Michael Scheffel, Einführung in die Erzähltheorie, München 1999, 47-67.

71 Inge Stephan, »>So ist die Tugend ein Gespenst<. Frauenbild und Tugendbegriff bei Lessing und Schiller«, in: Dies., Inszenierte Weiblichkeit. Codierung der Geschlechter in der Literatur des 18. Jahrhunderts, Köln u.a. 2004, 13-38, hier: 36.

72 Karl Lessing am 3ten Februar 1772 an Lessing (Anm. 8), 344.

73 Lessing (Anm. 8), 352.

74 Walter Benjamin, »Ursprung des deutschen Trauerspiels« (1928), in: Ders., Gesammelte Schriften, I.1, Frankfurt a. M. 1974, 285.
} 
»In der Tragödie«, so Goethe, bewirke die Katharsis eine Art Aussöhnung auf der Handlungsebene, und zwar »durch eine Art Menschenopfer, es mag nun wirklich vollbracht oder, unter Einwirkung einer günstigen Gottheit, durch ein Surrogat gelöst werden, wie im Falle Abrahams und Agamemnons «. ${ }^{75}$ Vor allem, wenn Goethe im Begriff des »Surrogats« den Aspekt der Stellvertretung ins Spiel bringt, berühren sich seine und die Gedanken Benjamins mit kulturanthropologischen Positionen, die den tragischen Helden als kulturelles Sublimat des Sündenbocks verstehen. Grie-

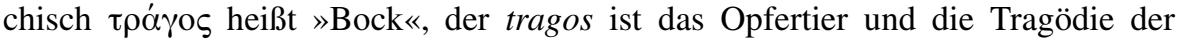
Gesang beim Bocksopfer. Bevor sie sich zu einer literarischen Gattung, zum Drama im eigentlichen Sinne entwickelte, war die Tragödie eine kultische Handlung, entstanden wohl im Kontext der Dionysos-Mysterien. ${ }^{76}$ Auf die dionysischen Wurzeln verweist noch die mänadische Ikonologie der rasenden Orsina in Szene IV/7. Spekuliert wird, die Tragödie sei aus dem Tieropfer entstanden, ${ }^{77}$ wenn nicht gar aus dem Menschenopfer, aus der rituellen Ermordung des Sündenbocks. Der Sündenbock ist das stellvertretende Opfer, und er stiftet, so René Girard, die Gemeinschaft qua Opfernachvollzug im Ritual und in der Erinnerung im Mythos. ${ }^{78}$ Im Zuge seiner Instituierung verwandelt sich der Sündenbock, zuvor Gegenstand der kollektiven Verachtung, in einen Gegenstand, der kollektiv verehrt wird. ${ }^{79}$ Der tragische Held ist sozusagen seine potenzierte, seine sublimere Stellvertretung. Auch seine Opferung reinigt die Gemeinschaft von der sonst frei in ihr flottierenden Negativität.

Eine Opferung wird im Rahmen eines Rituals vollzogen. Tatsächlich kann man in der Szene V/7 entscheidende Stadien eines förmlichen Opferrituals ausmachen. Und in der Emilia geschieht es nun wohl zum ersten Male, dass das Opfer selbst das Ritual bestimmt und sich als sacrificium auszeichnet. Emilia stirbt in einer sakramentalen Inszenierung, in der sich drei Komponenten unterscheiden lassen, die der Opferdesignation, dann die des Opferschmucks oder der Opfereinkleidung und schließlich die der Opferliturgie. Die Komponenten überlagern sich teilweise, folgen also nicht notwendig als diskrete Phasen oder Stadien aufeinander.

(1) Zunächst muss das Opfer als solches bezeichnet, es muss designiert, und es muss seine Exemplarität sichergestellt werden.

Die Exemplarität, der Stellvertretungscharakter, scheint zunächst noch nicht gegeben. »Ich stehe für nichts«, sagt Emilia, und meint damit nicht bloß, wie man

\footnotetext{
75 Johann Wolfgang Goethe, Sämtliche Werke nach Epochen seines Schaffens. Münchner Ausgabe, hrsg. Karl Richter usw., München 1985 ff, XII.1, $340 \mathrm{f}$.

76 Vgl. P. E. Easterling, »A Show for Dionysos«, in: Ders. (Hrsg.), The Cambridge Companion to Greek Tragedy, Cambridge 1997, 36-53.

77 Maßgeblich hierfür ist Walter Burkert, »Greek Tragedy and Sacrificial Ritual«, Greek, Roman and Byzantine Studies 7 (1966), 87-121, dt.: »Griechische Tragödie und Opferritual«, in: Ders., Wilder Ursprung. Opferritual und Mythos bei den Griechen, Berlin 1990, 13-39.

78 Vgl. René Girard, Das Heilige und die Gewalt, Frankfurt a.M. 1992.

${ }^{79} \mathrm{Zu}$ den religiösen Wurzeln der Tragödie und ihren Ursprüngen in Ritual und Opfer vgl. Isabelle Torrance, in: Rebecca Bushnell (Hrsg.), A Cultural History of Tragedy, 6 Bde., London 2019, I. Vgl. Erika Fischer-Lichte, Theater im Prozeß der Zivilisation, Tübingen, Basel 2000, 115: Theater folgt »der Struktur eines Opferrituals«.
} 
sonst meist herausliest, ${ }^{80}$ ihre Verführbarkeit durchs jugendlich warme Blut. Damit sie symbolisch für das Unrecht am weiblichen Geschlecht stehen und zum exemplarischen Opfer werden kann, zum individuellen Beispiel, das für etwas Allgemeines steht - ihre Initialen E.G. evozieren das »exemplum gratia «-, muss sie als solches ausgewiesen werden. Das besorgen einschlägig bedeutsame Dinge. ${ }^{81} \mathrm{Da}$ ist zunächst der Dolch als Designationsinstrument. Mehrfach musste Emilia ihn einfordern, bevor Odoardo ihn ihr in die Hand drücken sollte. Ihm wiederum war der Dolch von der Orsina aufgenötigt worden, wie die Regieanweisung in IV/7 explizit macht, und zwar mit bedeutungsvoll mehrdeutigen, zumal geschlechtersemantisch aufgeladenen Worten: »Nehmen Sie geschwind, eh uns jemand sieht. - Auch hätte ich noch etwas, - Gift. Aber Gift ist nur für uns Weiber; nicht für Männer. - Nehmen Sie ihn! ihm den Dolch aufdringend: Nehmen Sie!« (IV/7, 355) Gemeint ist das Gift als genuin weibliche Waffe, damit aber auch der Dolch als männliche Todesart. Wenn Emilia am Ende durch den Dolch stirbt, dann wird dieses Privileg auf sie übertragen und ihr Geschlecht einmal mehr geadelt.

(2) Ein Opfer wird zur Darbringung geschmückt. ${ }^{82}$ So auch Emilia, die Börne schon 1828 ein »geschmücktes Schlachtopfer« genannt hatte. ${ }^{83}$

Aber auch hier verhält sich Emilia nicht passiv. Sie selbst ist es, die sich schmückt. Sie selbst lädt zwei bislang bloß dekorative Accessoires symbolisch auf und erklärt sie dadurch zum Opferschmuck: Haarnadel und Rose. Die Haarnadel bringt Emilia ins Spiel, als ihr Vater zaudert: Solle sie sich etwa selbst, und zwar mit dem Galanterieartikel erstechen? Jetzt gerät dieses Ding in eine symbolische wie reale Substitutionsbewegung. Ich zitiere die Regieanweisung: »Sie fährt mit der Hand nach dem Haare, eine [Haarnadel] zu suchen, und bekömmt die Rose zu fassen.« (V/7, 369) Dass Emilia eine Rose im Haar trägt, war dem Stück bislang nur an einer einzigen Stelle zu entnehmen. Im siebten Auftritt des zweiten Akts bekräftigt ihr Verlobter Appiani den Code der empfindsamen Authentizität, der äußerlichen Putz und Geschmeide verachten heißt. Emilia eilt, sich umzukleiden, wie Appiani sie »in Gedanken« immer sieht, nämlich in den Habit der ersten Begegnung, bestehend aus einem schlichten, »fliegend und frei« geschnittenen Kleid und der nämlichen

\footnotetext{
80 Anders dagegen Susanne Lüdemann, »Weibliche Gründungsopfer und männliche Institutionen. Verginia-Variationen bei Lessing, Schiller und Kleist«, DVjs 87 (2013), 588-599, hier: 598.

81 Diesen Gedanken habe ich ansatzweise schon zu entwickeln versucht. Vgl. Verfasser: »Bewegte Dinge, bewegte Seelen. Vom Handeln der Dinge in Lessings Emilia Galotti«, in: Daria Dittmeyer, Jeannet Hommers, Sonja Windmüller (Hrsg.), Verrückt. Verrutscht. Versetzt. Zur Verschiebung von Gegenständen, Körpern und Orten, Berlin 2015, 27-38.

82 Vgl. Burkert (Anm. 77), 21. Andreas Bendlin u.a., »Opfer«, in: Der Neue Pauly, hrsg. Hubert Cancik u.a. https://doi.org/10.1163/1574-9347_dnp_e831660. (5. Juli 2018). Vgl. ferner die Einleitung »Ritualfundierung und Zeichendynamik des Opfers« zu Alexander Honold, Anton Bierl, Valentina Luppi (Hrsg.), Ästhetik des Opfers. Zeichen/Handlungen in Ritual und Spiel, München 2012, 7-14, hier: 13.

83 Börne (Anm. 38), 368.

84 Vgl. Jacques Lacan, »Das Seminar über Edgar Allan Poes >Der entwendete Brief««, in: Ders., Schriften I, 3. korr. Aufl., Weinheim, Berlin 1991, 7-60.
} 
Rose im Haar (II/7, 320). Das Requisit durchläuft also, lacanistisch gesprochen, ${ }^{84}$ die Register des Imaginären und des Realen: Aus Appianis Vorstellung wandert es als wirklicher Schmuck ins Haar, um dann in der Schlussszene ins Symbolische zu wechseln, um jetzt Emilia als Opfer zu schmücken.

(3) Schließlich stiftet Emilia ihre eigene Opferliturgie. Auf Ritus und Symbolik wird eine weitere, gleichsam sakramentale Schicht aufgetragen. Dem Ritus tritt jetzt der Mythos zur Seite.

Es sind denn auch zwei Erzählungen, >Narrative<, die zur Überwältigung Odoardos maßgeblich beitragen, indem sie ihre religiösen und politischen Energien wechselseitig verstärken. ${ }^{85}$ Zuerst rückt Emilia ihren Tod in die Nachfolge christlicher Märtyrerinnen: »Nichts Schlimmers zu vermeiden, sprangen Tausende in die Fluten, und sind Heilige! - Geben Sie mir, mein Vater, geben Sie mir diesen Dolch« (V/7, 369). Zudem verfolgt Emilia eine höchst wirksame psychologische Taktik. Sie fordert Odoardo als Mann und als Vater heraus. Indem sie an die römische Virginia-Legende appelliert, provoziert sie zugleich seine väterliche Männlichkeit: »Ehedem wohl gab es einen Vater, der seine Tochter von der Schande zu retten, ihr den ersten den besten Stahl in das Herz senkte - ihr zum zweiten das Leben gab. [...] Aber solcher Väter giebt es keinen mehr!«(V/7, 370) Im Virginia-Mythos ersticht ein Plebejer öffentlich seine Tochter, die das Gericht einem Patrizier zugesprochen hatte, und löst damit eine Revolte aus. Emilia selbst erkämpft sich das Martyrium, sie selbst verleiht ihm Bedeutung, indem sie polit-religiöse Modelle aus der Vergangenheit christologisch umdeutet: Sie selbst spricht im Sterben die sakramentalen Einsetzungsworte: »Eine Rose gebrochen, ehe der Sturm sie entblättert.« Nicht ohne ihrem zaudernden Vater zuvor bedeutet zu haben, worin der Sinn und damit die Zukunft des Tochteropfers besteht: Indem er sie tötet, indem er ihr »den ersten besten Stahl in das Herz« senkt, gibt er »ihr zum zweiten das Leben« (V/7, 370). Emilia wird auferstehen, indem in ihrem Namen gegen das Unrecht, das sie zur victima gemacht hat, angegangen wird. Der sakrale Charakter des Geschehens schlägt sich denn auch mehrfach nieder: Odoardo, der unmittelbar vor der Opferungsszene laut Regieanweisung einmal »gegen den Himmel« $(\mathrm{V} / 6,367)$ gesprochen hatte, ruft nach vollbrachter (Un-)Tat die transzendente Instanz an: »Gott, was hab’ ich getan!« (V/7, 370)

Ansonsten ist Odoardo Galotti, Vater der Emilia, in all diesen Vorgängen denkbar passiv. Er hält den Dolch, aber das Heft des Handelns führt die Tochter. Der Opferer wider Willen vermag nur noch, deren Worte, und vor allem deren Einsetzungsworte zu bestätigen: »Eine Rose gebrochen, ehe der Sturm sie entblättert «, diese intertextuell bald massenhaft zirkulierende Formel wird zuerst von Emilia ausgesprochen und dann, nach der Tat, von Odoardo identisch wiederholt (V/8, 370). Jetzt, in der Wiederholung, ist der Ritus als solcher konstituiert und das sacrificium vollzogen. Auch

\footnotetext{
85 Wenn Sørensen (Anm. 6), 93 meint, »die Tötung der Tochter durch den Vater [erfolge] nicht nur im Einverständnis beider [...], sondern auch als ein Akt familialer Liebe und Sittlichkeit«, geht er nicht in die Falle der meisten Interpretationen, dem Vater niedrige Beweggründe zu unterstellen. Allerdings verkennt er den Kampfcharakter der Auseinandersetzung, den Emilia mit dem ganzen Druck der Opfersemantik für sich entscheidet.
} 
darum versichert sich Odoardo bei der sterbenden Tochter, ob es mit der liturgischen Formel seine Richtigkeit gehabt hatte: »War es nicht so, meine Tochter?« Darauf lauten Emilias (vor)letzte Worte übrigens: »Nicht Sie, mein Vater - Ich selbst - ich selbst -« (V/8, 370; Hv. U. St.)

Könnte deutlicher bekräftigt werden, dass die Tochter, und nicht der Vater, das Opferritual stiftet? Wer Emilia als passives Opfer verstehen will, muss auch diesmal ihre Worte ignorieren. Sie selbst erkämpft sich ihr Martyrium, sie selbst stiftet die Liturgie, sie spricht die Einsetzungsworte, sie ist Opfer und sie ist Opferpriesterin zugleich. Das könnte durchaus als Anmaßung verstanden werden. Emilias Selbstopfer, verrät es womöglich das heikle Begehren, sich selbst zu heiligen, sich gottgleich zu machen ${ }^{86}$ Der Vater jedenfalls spricht ihr nur nach, gleichsam als Ministrant und erster Repräsentant der Gemeinde, in der nachgeordneten Position jedenfalls eines Erfüllungsgehilfen. Ihm bleibt jetzt nur noch, sich, wie eingangs dargestellt, auch explizit aus der tragischen Rolle zurückzuziehen: er habe nicht vor, seine »Tat wie eine schale Tragödie zu beschließen «.

\section{IV.}

In der Opferung wird also ein Körper, die Opfergabe, semantisiert. Die ihm verliehene Bedeutung beinhalte »ein besonderes Regenerationspotenzial für die Gesellschaft «. ${ }^{87} \mathrm{Im}$ Falle Emilias bekundet sich dies Potenzial bei genauerer Hinsicht in einer Reduktion: Ihr Opfer erlaubt oder fördert die Abbildung von gesellschaftlichen Konflikten auf eine Semantik der Geschlechter. Es gibt ja Gründe, warum sich so viele ältere feministische und jüngere genderwissenschaftliche Arbeiten der Emilia gewidmet haben, zumal in patriarchatskritischer Absicht. Sie können, indem sie das Monument als Dokument lesen, an Semantiken andocken, die, und das wird häufig übersehen, vom Stück selbst schon bereitgestellt werden. In und an Lessings Umwidmung des tragischen Opfers, das ist jetzt zu zeigen, arbeitet die zeitgenössische Geschlechteranthropologie mit, wie umgekehrt die um 1760 aufkommende kulturelle Semantik der Geschlechter nicht ohne den Beitrag des bürgerlichen Trauerspiels verstanden werden kann.

Bevor das Opferritual anhebt, bevor Emilia die Liturgie ihrer eigenen Opferung stiftet, und damit noch vor dem Verzicht des Vaters auf die tragische Position, den wir anfangs herausgestrichen hatten, geschieht etwas Bemerkenswertes. In einer auffällig selten kommentierten Passage hält Odoardo Galotti nämlich eine Lobrede auf das weibliche Geschlecht:

Ich hab' es immer gesagt: das Weib wollte die Natur zu ihrem Meisterstücke machen. Aber sie vergriff sich im Tone; sie nahm ihn zu fein. Sonst ist alles besser an Euch, als an Uns. - (V/7, 368)

\footnotetext{
86 Vgl. René Girard, Things Hidden since the Foundation of the World, Stanford 1978, 236f: »What might be concealed here [in self-sacrifice] is the desire to sacralize oneself and make oneself godlike - which clearly harks back to the illusion traditionally produced by sacrifice.«.

87 So Karin Peters, Der gespenstische Souverän. Opfer und Autorschaft im 20. Jahrhundert, München 2013, 98.
} 
Von Natur aus, so könnte man diese Worte paraphrasieren, wäre die Frau die Krönung der Schöpfung. Allenfalls ein kleiner Fehler sei der Natur unterlaufen: Sie habe die Frau aus zu feinem Tone, aus zu wenig widerständigem Material geschaffen. Warum ist das ein Fehler? Offenkundig, weil sie zu fein geartet scheint für die Härten, denen man draußen im Leben ausgesetzt ist, so zumal den Verführern und Intriganten am Hofe. Der Frauen allzu empfindliches Material ist also eigentlich gar kein Fehler. Wäre die Welt insgesamt nur so fein, so feinfühlig beschaffen, wäre sie eine bessere Welt. Die Frau repräsentiert das Gute, das einer Welt zum Opfer fällt, die aus ihrer Warte als verderbt bewertet werden muss. In exakt diesem Sinne sollte Lessings Wendung vom weiblichen als dem besseren Geschlecht starken Widerhall finden. 1798 publiziert der preußische Kriegsrat Erhard Valentin Jakob Sprengel ein Werk mit dem Titel Das andere Geschlecht, das Bessere Geschlecht. ${ }^{88}$ Der philanthropische Theologe und Erfahrungsseelenkundler Carl Friedrich Pockels schreibt 1805: »In diesen Rücksichten hat man es wagen [...] dürfen, das weibliche Geschlecht bisweilen das bessere zu nennen, weil es im Allgemeinen weniger egoistisch ist «. ${ }^{89}$

Ich verdanke diese Belege einem erstaunlichen und hellsichtigen Buch: Christoph Kucklick belegt in Das unmoralische Geschlecht. Zur negativen Andrologie der Moderne ${ }^{90}$ materialreich die These, im 18. Jahrhundert entstehe ein populäres anthropologisches Wissen von den Geschlechtern, und aus diesem töne ein cantus firmus deutlich hervor: Die von ihm so genannte »negative Andrologie«, der zufolge der Mann als ein von Natur aus unmoralisches Wesen der Zivilisierung durch die überlegene Moralität der Frau bedürfe. Anders als meist angenommen, beruhe die Geschlechtersemantik der Moderne gerade nicht auf einer generalisierten Unterordnung des Weiblichen unter das Männliche. Dass die Aufklärer und nachfolgende Generationen die Frau als unvernünftiges Naturwesen beschrieben, gar »aus der Sphäre des >Menschen $<$ ausgegrenzt $\ll^{91}$ und allein den Mann der Vernunft teilhaftig gewähnt hätten, stimmt in selteneren Fällen. Kucklick leugnet in keiner Weise, obgleich man ihm das mitunter vorgeworfen hat, die Existenz weiblichkeitsfeindlicher Semantiken. Er wertet indes eine imponierende Fülle von Quellen aus, darunter auch solche, die oft von feministischer Seite herangezogen wurden, um die These von der Subordinierung des weiblichen unter das männliche Geschlecht zu bekräftigen. Er kommt jedoch zu einem anderen Ergebnis: Mit verblüffender Regelmäßigkeit artikulieren die Geschlechteranthropologen des 18. Jahrhunderts - wohlgemerkt: Männer -, ein erstaunliches antimaskulines Ressentiment. Dieses wäre völlig dysfunktional, hätte man eine Überlegenheit des männlichen über das weibliche Geschlecht behaupten wollen. Ich folge Kucklick auch in der These, die Geschlechtersemantik der Moderne müsse als Überformung einer gesellschafts- bzw. modernitätseinschlä-

\footnotetext{
${ }^{88}$ Erhard Valentin Jakob Sprengel, Das andere Geschlecht, das Bessere Geschlecht, Berlin 1798. Vgl. Christoph Kucklick, Das unmoralische Geschlecht. Zur negativen Andrologie der Moderne, Frankfurt a. M. 2008, 16.

89 Carl Friedrich Pockels, Der Mann. Ein anthropologisches Charaktergemälde seines Geschlechts, Hannover 1805, II, 119. Vgl. Kucklick (Anm. 88), 88.

90 Kucklick (Anm. 88), 88.

91 Schößler (Anm. 46), 25.
} 
gigen Entwicklung, sie müsse quasi symbolisch verstanden werden. Wir reden, wenn wir über die Geschlechter reden, über unser Unbehagen an der Moderne. In ihr tritt Männlichkeit als sittliches wie als semantisches Integrationsprinzip der Gesellschaft tendenziell ab. Stattdessen findet die unentfremdete, sinnhafte Existenz ihr Symbol in aller Regel in einer neu konfigurierten Semantik der Weiblichkeit. Mehr und mehr nimmt das Korpus des sozialen Wissens und der Grundvorstellungen, das hat man des Öfteren schon festgestellt, weibliche Gestalt an. ${ }^{92}$

Kucklicks Beitrag zur Differenzierung einer recht homogen anmutenden, die Geschlechtscharaktere in der seit Karin Hausen festgeschrieben glaubenden Forschungslage $^{93}$ ist selbst mitunter der Einseitigkeit geziehen worden. Dabei lässt er, wenn er die Idee einer »>schlechten< Männlichkeit [...] als eigentlichen Ankerpunkt des modernen Geschlechterverhältnisses « ${ }^{94}$ beschreibt, keinen Zweifel daran aufkommen, dass sich die aufkommende Moderne auch in Behauptungen einer defizitären Weiblichkeit gespiegelt hatte. ${ }^{95}$ Und er verweist auf Autorinnen, die das Ressentiment gegen das Maskuline, das immer auch ein maskulines Ressentiment gewesen ist, zuvor schon ausgemacht hatten. ${ }^{96}$ Systematisch nachgegangen wurde ihm jedoch nicht. In der Regel war man mit Ute Frevert der Meinung, das »Konzept >Mann«« sei »sehr viel später als der Kollektivsingular >Frau< zum Gegenstand konkurrierender ideologischer Bedeutungen « geworden; ja, Frevert konnte sich im Lichte ihrer Quellen, vornehmlich Konversationslexika, »des Eindrucks nicht erwehren, als sei der >Mann « für das bürgerliche 19. Jahrhundert weitgehend unproblematisch gewesen $\ll .{ }^{97}$

Das war er nicht, und das war er schon im 18. Jahrhundert nicht, wie Kucklick seiner umfänglicheren Quellenbasis entnehmen konnte. Gleichwohl wären seine Befunde zu ergänzen. Die schöne Literatur spielt bei ihm, dem Soziologen und Kulturwissenschaftler, kaum eine Rolle. Dabei spricht einiges für die These, dass das bürgerliche Trauerspiel der Geschlechteranthropologie den Boden bereitet habe. ${ }^{98}$ Negativ andrologische Semantik scheint auf der Bühne früher artikuliert worden zu sein als in den anthropologischen Traktaten über Männer und Frauen, die im letzten Drittel des 18. Jahrhunderts und bis weit in 19. hinein florieren. ${ }^{99}$ Schon in

\footnotetext{
92 »The body of social knowledge and conjecture conforms more and more to the female shape «, Lionel Tiger, The Decline of Males, New York 1999, 3.

93 Vgl. Sørensen (Anm. 6), 31-34.

94 Kucklick (Anm. 88), 15.

95 Kucklick (Anm. 88), 18.

96 Kucklick (Anm. 88), 18, 19.

97 Ute Frevert, »Mann und Weib, und Weib und Mann«. Geschlechter-Differenzen in der Moderne, München 1995, 57.

98 Kucklick (Anm. 88) verzeichnet kaum eine vor 1760 datierende Quelle. Geschlechteranthropologische Traktate häufen sich erst in der letzten Dekade des 18. und in der ersten des 19. Jahrhunderts.

99 Zu nennen wären neben Pockels auch Fichtes Deduktion der Ehe aus der Grundlage des Naturrechts und sein System der Sittenlehre, die dem Mann einen blind wirkenden »Geschlechtstrieb « und einen »sehr unmoralisch wirkenden Charakter« unterstellen (Kucklick [Anm. 88], 122). Ferner Wilhelm von Humboldt, der 1795 vom »uncultivierte[n] männliche[n] Naturcharakter« sprach. Zum vollwertigen Menschen werde der Mann erst, wenn er seine Geschlechtsnatur negiert und sich die Tugenden des Weiblichen angeeignet habe. Vgl. Kucklick (Anm. 88), 75.
} 
Pfeils Lucie Woodvil, Anknüpfungs- und Abstoßungspunkt Lessings, fällen Figuren einschlägige Verdikte, die die Position des Verführers als Ausdruck geschlechteranthropologischer Defizite markieren: »Kannte ich sein Geschlecht nicht«, sagt dort die Titelfigur über Karl, ihren Liebhaber und noch unerkannten Halbbruder, »dies Geschlecht, das nur uns [Frauen; U. St.] unglücklich zu machen geschaffen zu sein scheint? [...] Wäre Karl der beste unter dem männlichen Geschlechte, was konnte er weniger sein als ein Betrüger?« Bereits Pfeils Erfolgsstück inkriminiert den »allzu harten Vater «, dem eine »zaertlich(e) Mutter « gegenübersteht. ${ }^{100}$

Seit damals wächst der kulturelle Argwohn gegen Männlichkeit. Folglich spiegelt sich auch der Abstieg vom sorgenden Patriarchen zum finsteren Gesellen in der Deutungsgeschichte des Odoardo Galotti. Ein Stahlstich von Carl Mayer zeigt ihn als edlen Patriarchen, der sich dem Adel entgegen und vor seine Tochter stellt (Abb. 1). ${ }^{101}$

1803 hatte Johann Friedrich Bolt in der Scene aus Emilia Galotti den Vater als finster entschlossenen Grämling dargestellt. In seiner Darstellung fehlt jedoch signifikant der Adel (Abb. 2). ${ }^{102}$

Neu an der tragischen Lösung der Emilia ist nun nicht, dass eine Frau die Position des tragischen Helden und ein Mann die des Täters bekleidet. Das gab es seit je. Neu erscheint vielmehr, dass Weiblichkeit und Männlichkeit expliziter Reflexion zugeführt und zumal mit einer Reflexion der tragischen Position selbst verknüpft werden. Darin ist Lessing hochgradig innovativ und einflussreich. Und in eben diesem Zuge bedeutet für ihn das weibliche Geschlecht das bessere Geschlecht. Diese negativ andrologische Sicht sollte Schule machen, auch wenn Zeitgenossen sie mitunter übelnahmen. In der Hamburgischen Neuen Zeitung vom 25. April 1772 fordert ein anonymer Beiträger den Verfasser der Emilia Galotti auf, sich zu rechtfertigen, dass er »das männliche Geschlecht dem weiblichen nachzusetzen angefangen hat «. ${ }^{103}$ Der Briefschreiber spielt dabei frühere Werke Lessings, insbesondere die Miß Sara Sampson, gegen die Emilia und gegen die Minna aus: Was wären Sir Sampson und Waitwell doch noch für vorbildhafte, weil empfindsame Männer gewesen, sie »sind sanft, die Gutheit, der Trieb zur Uebereinstimmung scheint die Triebfeder ihrer Rechtschaffenheit zu seyn«. Odoardo Galotti und Major von Tellheim jedoch sind »rauh«, »Stolz, die Unbiegsamkeit scheinen die Triebfeder ihrer Größe zu seyn «. ${ }^{104}$ M.a.W.: Dieser anonyme, mit dem Werk Lessings gut vertraute Zeitgenosse bemängelt nicht die weiblich codierten Tugenden der Empfindsamkeit, wie sie noch Sir Sampson ausgezeichnet hatten. Dies, und damit den Modellcharakter der Weiblichkeit für eine vernünftige und vorbildliche Sozialität, scheint er zu akzeptieren. Er

\footnotetext{
100 Pfeil (Anm. 41), 27, 10.

101 Abb. 1: »Emilia Galotti«. Stahlstich von Carl Mayer (1802-1872) nach Zeichnung von Johann Georg Buchner (1815-1857). Aus: A. Schott (Hrsg.), Panorama der deutschen Klassiker, Stuttgart (K. Göpel) o. J., Frontispiz. Berlin, Sammlung Archiv für Kunst und Geschichte. Bildnummer AKG244157.

102 Johann Friedrich Bolt, Scene aus Emilia Galotti (1803). (C) Kupferstichkabinett Berlin, Inv.-Nr. 17-44. Ich danke Stephanie Wollmann für die Recherche.

103 Zit. n. Hans Henning, Lessings »Emilia Galotti« in der zeitgenössischen Rezeption, Leipzig 1981, 199-202, hier: 199.

104 Zit. n. Henning (Anm. 103), 199 f.
} 
Abb. 1 Lessing, Emilia Galotti / Ill. v. Buchner. Berlin, Sammlung Archiv für Kunst und Geschichte. Bildnummer AKG244157

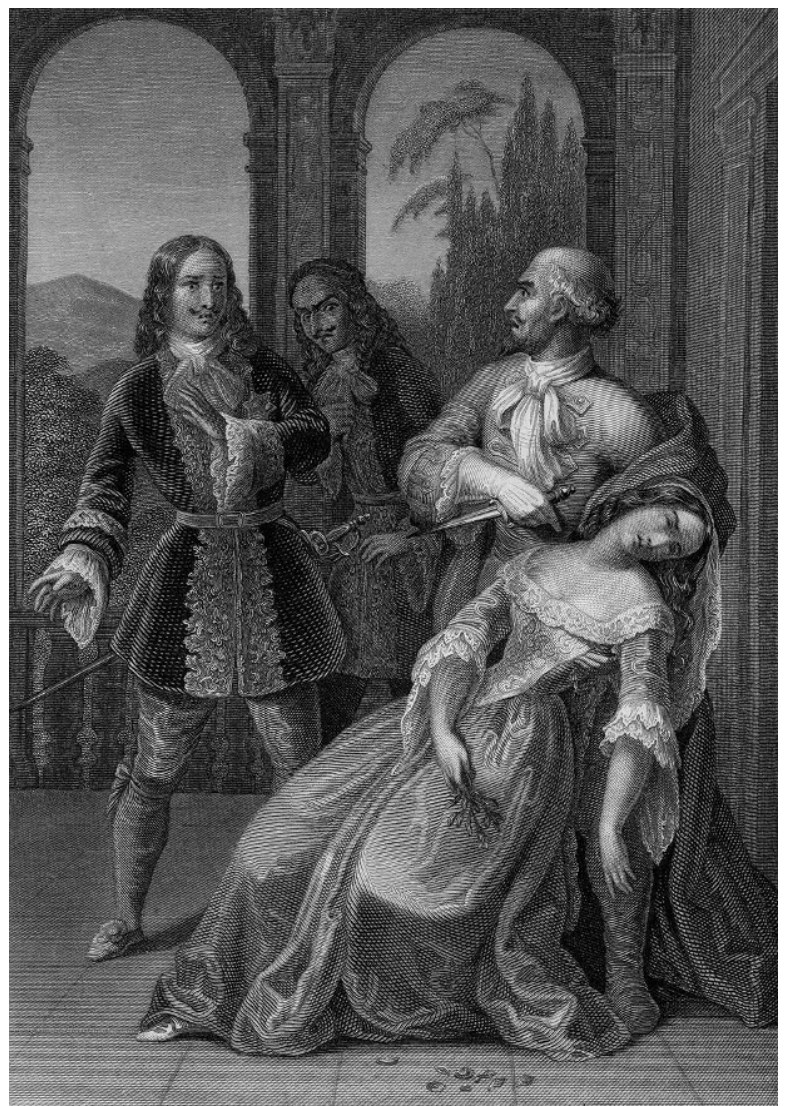

nimmt vielmehr Anstoß daran, dass Lessing die Männer jetzt nicht mehr an diesen Werten teilhaben lässt. Der sensible Zeitgenosse hat demnach den Schwenk Lessings in Richtung einer negativen Andrologie wahrgenommen.

Umso dringlicher muss nach dem Grund für die Worte Odoardos gefragt werden. Warum geht am Ende, und zumal im unmittelbaren Vorfeld eines Opferrituals, Geschlechtersemantik in den Handlungs- und Motivierungszusammenhang der tragischen Katastrophe ein? Lessing wäre nicht der dramaturgische Könner, der er ist, hätte er nicht auch dieses ebenso erstaunliche wie erstaunlich unbeachtet gebliebene Moment vorbereitet. Jetzt wird klar, wie sehr die Worte der Orsina in der Szene IV/7 Odoardo beeindruckt hatten. Die abgelegte Mätresse steigert sich nämlich »wie in der Entzückung« in eine Rachevision hinein, die sie als »himmlische Phantasie« deklariert:

Wann wir einmal alle, - wir, das ganze Heer der Verlassenen, wir alle in Bacchantinnen, in Furien verwandelt, wenn wir ihn alle unter uns hätten, ihn unter uns zerrissen, zerfleischten, seine Eingeweide durchwühlten, um das Herz zu finden, das der Verräter einer jeden versprach, und keiner gab! (IV/7, 356) 
Abb. 2 Johann Friedrich Bolt, Scene aus Emilia Galotti (1803). (C) Kupferstichkabinett Berlin, Inv.-Nr. 17-44

Schon hier, im Rasen der Orsina, drückt sich der tiefe Zusammenhang zwischen Empfindsamkeit und Grausamkeit aus, wie er ungleich radikaler einige Jahrzehnte später in einem Opferdrama kulminieren wird, das ohne Lessings Vorbild undenkbar wäre, in Kleists Penthesilea. Dabei aktualisiert die Gräfin zwei mythologische Muster: ${ }^{105}$ Einerseits tritt sie als Furie auf, als eine der einschlägig matriarchal konnotierten Rächerinnen, die im Atridenstoff die Beleidigung des Mutterrechts ahnden. In ihrer Verzückung geriert sie sich andererseits als Mänade, als bacchantisch Enthusiasmierte. Vom weiblichen Gefolge des Tragödiengotts Dionysos wird in den Bakchen des Euripides bekanntlich Pentheus zerrissen, König und Mann, der sich frevelnderweise maskiert in den weiblichen Exzess eingeschlichen hatte. Musste der nachgiebige Odoardo vor dieser geballten Macht der mythologischen, religiösen und politischen Narrative, vor Furien, Mänaden, Märtyrerinnen und Virginien nicht zwangsläufig kapitulieren? Vielleicht noch nicht einmal, wäre nicht noch ein weiteres Moment hinzugekommen:

Im bacchantischen Taumel spricht die Gräfin im Namen ihres Geschlechts, im Namen eines »wir«, das alle Betrogenen, das »ganze Heer der Verlassenen«, umfasst. Sie ist nicht mehr nur die abgelegte Mätresse und darin Leidtragende einer schichtenspezifischen sozialen Praxis, in der der Primat der Allianzheirat durch die auch adligen Frauen offenstehende Option der außerehelichen Affäre flankiert wurde. Von

105 Vgl. Dieter Borchmeyer, »Mozarts rasende Weiber im Gegenlicht der Empfindsamkeit«, in: Ders., Mozart oder Die Entdeckung der Liebe, Frankfurt a.M. 2005, 90-141, hier: 95 f. 
Galanterie will sie nichts wissen. Vielmehr ruft sie unter empfindsamem Vorzeichen als betrogene Frau zu den Waffen, sie mobilisiert im Namen ihres Geschlechts. Das Soziale wird auf ein geschlechteranthropologisches Muster abgebildet. Folglich spricht auch Emilia im Namen ihres Geschlechts, und sie streicht das durch das rhetorische Mittel der Geminatio noch einmal in aller Prägnanz heraus: »Als ob wir, wir keinen Willen hätten, mein Vater!«(V/7, 369. Hv. U. St.) Damit rücken sowohl die Orsina als auch Emilia den Verführer komplementär in eine durch sein Geschlecht definierte Gruppe ein.

Spätestens jetzt, am Ende des vierten Akts, in der mänadischen Ekstase der Orsina, zeigt sich der tragische Konflikt durch den Gegensatz zwischen Männlichkeit und Weiblichkeit überformt. Und zwar gerät in dieser Verschiebung von Gesellschaft auf Geschlecht Männlichkeit unter Anklage. Es ist diese Anklage, auf die Odoardo mit seiner Lobrede reagiert. ${ }^{106}$ Er muss sich mitgemeint fühlen, wenn die Anklage geschlechteranthropologisch fokussiert wird. Wird man aber einer Schuldgruppe zugerechnet, bleibt nur die Option, Demut und Läuterungsbereitschaft zu zeigen. ${ }^{107}$ In Lobrede und Verzicht auf die tragische Würde sucht Odoardo Männlichkeit abzubüßen, sich den Bonus geläuterter Männlichkeit zu erwerben. Noch dem Major von Tellheim musste eine vergleichbare Läuterung überhaupt erst vermittelt werden, und zwar durch eine weibliche Intrige: »O, über die wilden, unbiegsamen Männer, die nur immer ihr stieres Auge auf das Gespenst der Ehre heften! für alles andere Gefühl sich verhärten!«, sagt Minna von Barnhelm. ${ }^{108}$ Mittels animalischer Metaphorik negativ andrologische Semantik evozierend, ist sie es, die als sittliche Instanz spricht. Odoardo Galotti, der die Rolle des empfindsamen Hausvaters bislang nur unvollkommen ausgefüllt hatte, dessen »stren[ge] Tugend « (II/4, 148), wenig später seine »rau[he] Tugend « (II/5, 149) oder seinen rasch auflodernden »Zorn« (II/6, 151) seine Gattin beklagt hatte, Odoardo, der seine Affekte nicht kontrollieren und die nötige Zärtlichkeit nicht aufbringen kann, steht am Ende als in Teilen geläuterter, zumindest aber läuterungsbereiter Mann dar. Das Stück misst also die Fallhöhe eines Menschen aus, der eingangs als »das Muster aller männlichen Tugenden« (II/7) bezeichnet wird, am Ende jedoch eingestehen muss, am weiblichen Geschlecht sei »alles besser « als an seinem.

Mit all dem soll nicht behauptet werden, dass der Charakter des Odoardo stimmig konstruiert sei. Auch hier dürfte es eher die Bildmächtigkeit einer opferlogischen Konstellation gewesen sein, die der Figur ihre anhaltende Resonanz und kontroversen Qualitäten verschaffen konnte. Ihr expliziter Verzicht auf die Würde des

\footnotetext{
106 Die zeitgenössisch sehr beachtete Lobrede wird in der Forschung, wie gesagt, verblüffend selten überhaupt nur erwähnt. Einer der wenigen, der ihre Wichtigkeit erkennt, ist Lothar Pikulik, »>Sonst ist alles besser an Euch, als an Uns<. Über Odoardos Lobrede auf die Frau in Emilia Galotti«, in: Hans Edwin Friedrich et. al. (Hrsg.), Bürgerlichkeit im 18. Jahrhundert. Studien und Texte zur Sozialgeschichte der Literatur, Tübingen 2006, 303-322, hier: 316: Pikulik erkennt Lessings »positives Frauenbild«, und er begreift die Rede als »Akt poetischer Gerechtigkeit, der ein Unrecht in der Realität kompensiert «. TerNedden (Anm. 54), 235, bringt hingegen das Kunststück fertig, noch die Lobrede als Ausdruck defizitärer Männlichkeit hinzustellen.

107 Vgl. Sandra Kostner (Hrsg.), Identitätslinke Läuterungsagenda. Eine Debatte zu ihren Folgen für Migrationsgesellschaften, Stuttgart 2019.

108 Lessing, Minna von Barnhelm IV/6. Werke (Anm. 24), I, 679. Hv. U. St.
} 
Tragischen hat die ambivalenten Wirkungen erst herausgefordert. Noch für Friedrich Nicolai stellte sich Odoardo »erhöhet « dar, auch wenn sein Autor diese Wirkung noch stärker hätte herausstreichen können. Im schon zitierten Brief an Lessing fragt Nicolai nämlich, ob

Odoardos Charakter nicht noch mehr erhöhet worden [wäre], wenn Orsina aus Rache vergebens versucht hätte, ihren Liebhaber zu erstechen, dieser aber aus Tugend seine Tochter wirklich ersticht? ${ }^{109}$

Dem Freund des Autors darf man eine konsensuelle, wenn nicht sympathetische Wahrnehmung unterstellen. Nicolai wollte in Odoardos Tat noch ein sacrificium, die Anwartschaft auf die tragische Position, erkennen, auf die der Vater Verzicht leistet. Wenn Nicolai von der »Erhöhung « Odoardos spricht, die Lessing, wenn auch unvollkommen, bezweckt habe, mag er an die Opferung Isaaks durch Abraham gedacht haben. Das Opfer Isaaks in Genesis 22, 1-19 werden Martin Buber und Franz Rosenzweig mit dem Wort »Darhöhung « übersetzen. ${ }^{110}$ Der Mythos Abraham erzählt von der Einsetzung des Patriarchen. Abraham ist bereit, auf Geheiß Jahwes das ihm Liebste, seinen Sohn zu opfern, ohne den Sinn einzusehen. In »dieser für die europäische Kultur paradigmatischen Szene [...wird] der Vater [...] instituiert als derjenige, der den Sohn im Bezug zum Morde bindet und entbindet, und er nimmt diese Bindung und Entbindung für seinen Sohn und für sich selbst vor«, so wie er von Jahwe »zunächst gebunden und dann wieder entbunden« worden ist. ${ }^{111}$ Emilia kehrt nicht nur die patriarchale Relation um, indem sie es ist, die ihren Vater bindet. Und zwar im Namen eines Dritten, erfolgt doch Bindung immer im Namen eines anderen. Emilia bindet im Namen ihrer Geschlechtergruppe. Ihre Opferung aber, die aller christologischen Anklänge und aller Märtyrersemantik zum Trotz eher auf mänadische Modelle rückverweist, lässt den eigentlichen Schritt, den Schritt, der das Gesetz konstituiert, nämlich die Entbindung, vielmehr aus. Vor ihren Augen findet Odoardo keine Gnade.

Und auch nicht vor denen des Publikums. Nach ihm war auch der Mainstream der Rezeption nicht bereit, Odoardo erhöht zu finden oder ihm wenigstens den Läuterungsbonus zuzugestehen. Von Bodmer bis Ter-Nedden und vielen anderen wurden ihm niedere Beweggründe unterstellt. Warum? Schlug sich hier die schon konstatierte Verschiebung von der Darstellung auf das Dargestellte nieder? Anstelle der Konstruktion des Tragischen fasste man die Charaktere ins Auge und suchte nach den Schuldigen an der Katastrophe. Man war quasi der Logik des neuen Opfers aufgesessen. Die Sakrifizierung der Victima erheischte Sündenböcke, denen die Würde des Tragischen abging. Im Zuge des kritischen Unternehmens bedurfte es einer Schuldgruppe. Die Konstruktion der Tragödie erleichterte den Fund. Das liegt in der Repräsentationslogik des Opfers begründet, die das Stück einmal selbst namhaft zu machen wusste: »In seinem Zorne«, heißt es von Odoardo, »hätt' er den unschuldigen Gegenstand des Verbrechens mit dem Verbrecher verwechselt« (II/6).

\footnotetext{
109 Brief an Lessing vom 7. April 1772, Lessing (Anm. 8), XI/2, 389.

110 Vgl. Michael Niehaus, Wim Peeters (Hrsg.), Mythos Abraham, Stuttgart 2009, 44.

111 Pierre Legendre, Das Verbrechen des Gefreiten Lortie. Abhandlung über den Vater, Freiburg 1998, 33. Ich danke Wim Peeters, der mir die Relevanz Legendres vermittelt hat.
} 
In diesem Zuge hat Lessings geschlechtersemantische Codierung eines sozialpolitischen Konflikts eine Peripetie in der Literatur- und Kulturgeschichte eingeleitet. In ihr wird quasi der Zusammenhang zwischen Opferkultur und Identitätspolitik gesetzt. Auch das ist buchenswert: In dem Moment, in dem Odoardo gegen die adlige Ehre für eine Kultur der Würde eintritt, unterminiert seine Tochter dieselbe. Indem sie das bacchantische Kultopfer in ein sakrifizielles Selbstopfer ${ }^{112}$ umwidmet, setzt sie ein Fanal für eine nachmalig so zu nennende Opferkultur. ${ }^{113}$ In seinem Namen konnte, wie erwähnt, das in den Gattungskonventionen des bürgerlichen Trauerspiels versammelte semantische Arsenal der Hofkritik ${ }^{114}$ auf die moderne Gesellschaft übertragen werden. Jetzt wird wahlweise die schlechte Äußerlichkeit der Öffentlichkeit und der Funktionssysteme kritisiert, aber auch die Realität der Familie an den empfindsamen Werten gemessen und für kritikbedürftig befunden. Weil schon früh die Opposition zwischen der moralisch korrupten Hofsphäre bzw. der Öffentlichkeit und dem Gefühlsraum der Familie durch die Geschlechteropposition überformt wurde, konnte bald darauf die Negativität der Moderne generell im Manne symbolisiert werden. Die Geschlechteranthropologie beschreibt ihn daher stereotyp als Wesen, die von Natur aus gewalttätig, egoistisch, asozial, hypersexuell, gefühlskalt und kommunikationsunfähig sei. »Viele Thiere werden ganz aussterben«, schrieb Friedrich Schlegel, »so auch das Geschlecht der Männer «. ${ }^{115}$

\section{V.}

Nach all dem müsste die lange vertretene Meinung eigentlich rätselhaft erscheinen, Lessing dokumentiere »wie die zeitgenössische aufklärerische bürgerliche Werteskala mit einer geradezu [...] unmenschlichen Geschlechterpolitik einhergeht «. ${ }^{116}$ Gemeint ist, sie wäre Frauen gegenüber unmenschlich gewesen. Wenn die »Ermordung [!]« Emilias wirklich auf effektvolle Weise »einen bürgerlich-paternalen Herrschaftsanspruch « hätte veranschaulichen sollen, ${ }^{117}$ dann wäre die Kalkulation schlecht aufgegangen. Vielmehr bezeugt die Emilia, und es bezeugt ihre Rezeption eine Demontage männlicher Hegemonie. Wenn das Stück als Dokument begriffen werden kann, dann als eines für die Erosion patriarchaler Mächte schon im 18. Jahrhundert. Der so oft als Familientyrann verzeichnete, wahlweise einer rigoristischen Tugendethik oder einer aggressiven Männlichkeit, wenn nicht beider zugleich geziehene Odoardo Galotti wird in Wahrheit als ein schwacher Hausvater vorgeführt, der keiner Frau etwas abschlagen kann. Gegen seine Überzeugung erfüllt er seiner

\footnotetext{
112 Vgl. Katja Malsch, Literatur und Selbstopfer. Historisch-systematische Studien zu Gryphius, Lessing, Gotthelf, Storm, Kaiser und Schnitzler, Würzburg 2007.

113 Vgl. Campbell, Manning (Anm. 43). Giglioli (Anm. 67).

114 Vgl. Kiesel (Anm. 45).

115 Friedrich Schlegel, »Philosophische Fragmente. Erste Epoche. III. [1797-1801]«, in: Ders., Kritische Friedrich-Schlegel-Ausgabe, hrsg. Ernst Behler, Jean-Jacques Anstett, Hans Eichner, Zürich 1958ff., 2. Abteilung, XVIII, 188, Nr. 741.

116 Dorothea von Mücke (Anm. 47), 172.

117 Nitschke (Anm. 22), 87.
} 
Frau Claudia den Wunsch, in der Stadt und damit in der verhängnisvollen Nähe des Hofes zu wohnen. Von der Orsina lässt er sich den Dolch aufdrängen, den er zum grässlichen Ende auf Verlangen seiner Tochter einsetzt, nicht ohne zuvor auf die höhere Moralität des weiblichen Geschlechts verwiesen zu haben. Und deren Opferung stellt auch keinen Akt der Souveränität dar, zumindest nicht der seinen, als vielmehr einen des Verzichts. ${ }^{118}$

Wie hatte man das ignorieren können? Wie vermochten feinsinnigste und jedes Wort sorgfältigst abwägende Lessing-Kennerinnen und -Kenner an den offenkundigen Textbefunden vorbeizulesen? Warum überlas man das Frauenlob in dem Maße, in dem man Odoardos Verzicht auf die Würde des Tragischen stillschweigend überging? Auf diese Fragen gibt es keine einfache Antwort. Interpretationen sind immer irgendwie befangen, natürlich auch die hier vorgestellte. Es zeichnen aber auch der Gegenstand und die Problematik des tragischen Schlusses mit verantwortlich. In der Emilia Galotti kulminiert eine veritable Krise der Tragödie. Diese Form des Tragischen reinigt nicht mehr.

Gewiss, Ter-Neddens These, die tragische Katastrophe sei gar nicht zwingend, kam einem Geniestreich gleich. Jetzt konnte man dem Autor auch dort souveränes Kalkül, poetologische Meisterschaft und vor allem ein moral- und sozialpolitisches Wirkungswollen unterstellen, wo eine lange Tradition die Motivation der Katastrophe oder die Zeichnung der Charaktere bemängelt hatte. Wie sich aber die unterstellte höhere Intention hinter der angeblich bewusst fadenscheinig geknüpften Katastrophe mit der Ästhetik des Theatercoups vereinen ließe, mit der Ausstellung des Grässlichen und der Wirkung des Entsetzlichen, darüber schwieg sich die These aus.

Und doch trifft Ter-Nedden ja etwas. Der tragische Tod Emilias erfolgt nicht zwingend. Dennoch vermochte er seine überwältigende Wirkung auszuüben. Und zwar mit all seinen Rätseln, Inkonsistenzen oder Leerstellen in der Konstruktion der Katastrophe, mit seinen mythologischen und religiösen Mustern. Lessing gelang es, das Rätsel des selbstgewählten Martyriums, der Selbstdesignation als Sacrificium, in dem die Titelheldin den eigenen Status als Victima sakralisiert, in ein nicht rational, aber ästhetisch überwältigendes, symbolisch wirksames Bild zu verdichten. Es konnte in einer ganz bestimmten historischen Lage, in der zumal die geschlechteranthropologische Umdeutung sozialer Problemlagen auf den Plan trat, eine derart überwältigende Resonanz erfahren. So konnte der Theatercoup Folgen zeitigen und weitere Erschütterungen auslösen.

Wenn die Intrige einerseits exakt kalkuliert, ja, Produkt einer »dramatischen Algebra « (Schlegel) ist, die tragische Lösung indessen nicht eigentlich notwendig erscheint, wenn mithin der Zufall seinen maßgeblichen Faden ins Gewebe der schein-

\footnotetext{
118 Im Anschluss u.a. an Giorgio Agamben hatte man in Odoardos Tat einen Akt der Souveränität im Ausnahmezustand wahrnehmen wollen. Vgl. Nitschke (Anm. 22), 133 ff. u.Ö. Emilias Leben ist aber kein nacktes Leben und die Tat Odoardos weder rechtlich noch psychologisch eine souveräne. Schon Wilfried Wilms, »Im Griff des Politischen - Konfliktfähigkeit und Vaterwerdung in Emilia Galotti«, DVjs 76 (2002), 50-73, verstand Odoardos Handeln als Behauptung einer Souveränität über die Familie, in der Gewalt- und Opferbereitschaft das Politische konstituierten. Ist der tragische Tod Emilias aber allein Odoardos Tat? Und meines Wissens erwarten weder Carl Schmitt, auf den sich Wilms beruft, noch Agamben vom Souverän, dass er sich nach seinem souveränen Akt einem Richter stellt.
} 
baren Notwendigkeit einträgt, dann entspricht diese Gleichzeitigkeit von zwingender Kausalverkettung auf der einen und einem kontingenten Resultat auf der anderen Seite dem zentralen Strukturmerkmal einer Gattung, die es noch gar nicht gibt: nämlich dem Slapstick. Dieser Bezug liegt nicht so fern, wie es zunächst den Anschein hat. Das Tragische in der Emilia Galotti, und das ist keine neue Erkenntnis, unterhält subkutane Beziehungen zum Komischen. Schon früh schallte Gelächter in das entsetzte Stöhnen angesichts der Katastrophe hinein. Eva König berichtet Lessing am 15.7.1772, das Stück habe in Wien zwar außerordentlichen Beifall errungen. Der Kaiser aber habe in seinem Leben »in keiner [Tragödie] so viel [...] lachen hören; zuweilen bei Stellen, wo [...] eher hätte sollen geweinet, als gelachet werden «. ${ }^{119}$

In diesen Zusammenhang gehört auch die Beobachtung Karl Eibls, die tragische Katastrophe sei kaum auf einen metaphysischen Schuldbegriff zurechenbar, sie sei vielmehr durch eine Verkettung von »Fehl-Berechnungen « ausgelöst worden. ${ }^{120}$ Auch hat man die Ähnlichkeit zwischen der tragischen Intrige und genuin komödienhaften Verwicklungen auf strukturelle und charaktertypologische Merkmale der commedia dell'arte zurückgeführt, die Lessing ja intensiv rezipiert hatte. Wenn sich ein tragischer Inhalt nurmehr ins Formmodell der Komödie fügt, trete an die Stelle eines tragischen Weltbildes die Anklage politischer Missstände. ${ }^{121}$ Diesen Zusammenhang zwischen den Genres des Komischen und einer moralpolitischen Wirkungsabsicht hatte schon Goethe an der Emilia erkannt, genauer: ihr angekreidet. ${ }^{122}$ Im 1812/1813 diktierten dritten Teil von Dichtung und Wahrheit attestierte er dem Stück, es habe einen um 1770 moralisch hochgradig aufgeregten Zeitgeist maßgeblich mit aufgeheizt, in dessen Wogen auch das Theater »eine Wendung nach dem Sittlichen « genommen habe. Goethe begriff die Emilia als Repräsentantin einer Mode, die sich vor allem in Lustspielen und Satiren kundtue. In ihr gipfele die Tendenz eines politmoralischen Konformismus, der nicht etwa durch Mitleid bessere Menschen hervorbringt, sondern den Geist der Schadenfreude bedient, indem er Sündenböcke in den höheren Ständen sucht. ${ }^{123} \mathrm{Ob}$ Goethe recht hat, sei dahingestellt. Im Hinblick auf das forcierte tragische Ende der Emilia läge es zumindest nahe, die Mitleidsästhetik um eine dramenpoetologische Reflexion der Stellvertreterempörung und ihrer Mechanismen zu ergänzen.

In der Dramaturgie des Zufalls fällt die Krise der Tragödie mit der der Theodizee zusammen. »Das Wort Zufall ist Gotteslästerung«, lässt Lessing die Orsina (IV/3) sagen. Aus dem Scheitern der Theodizee ging bekanntlich die Idee von der Geschichte als einem Prozess hervor, in dem der Mensch in Sachen Übel der Welt zum absoluten Ankläger und zugleich zum absoluten Angeklagten wird. ${ }^{124}$ Die Emilia dokumentiert

\footnotetext{
119 Briefe von und an Lessing 1770 - 1776. Lessing, Werke und Briefe in zwölf Bänden (Anm. 4), XI/2, 442.

120 Eibl (Anm. 27), 154.

121 Klaus-Detlef Müller, »Das Erbe der Komödie im bürgerlichen Trauerspiel. Lessings Emilia Galotti und die commedia dell'arte«, DVjs 46 (1972), 28-60.

122 Zum Folgenden vgl. ausführlicher Verf.: »Für sich und andere vielleicht« (Anm. 3).

123 Johann Wolfgang Goethe, Dichtung und Wahrheit, Münchner Ausgabe (Anm. 75), XVI, 601 und 603.

124 Vgl. Odo Marquard, »Der angeklagte und entlastete Mensch in der Philosophie des 18. Jahrhunderts«, in: Ders., Abschied vom Prinzipiellen. Philosophische Studien, Stuttgart 1981, 39-66, hier: 49. Schon Prutti
} 
und bedient mithin jene Tendenz, die Odo Marquard als Übertribunalisierung bezeichnen sollte. Wenn die tragische Katastrophe nicht mehr unvermeidlich scheint, kein Fatum, keine Hamartia, kein schuldloses Verschulden mehr waltet, wenn an ihre Stelle eine geschlechteranthropologisch unterfütterte Opferpolitik tritt, wenn sich also der Fokus von der Darstellung aufs Dargestellte verschiebt, dann stellt sich die Frage nach der Schuld der Figuren an der Tragödie und an den sozialhistorischen und politischen Verhältnissen, für die sie verantwortlich zeichnen.

Zugleich bedeutet der Emilia Scheitern in der Konstruktion des Tragischen ein entscheidendes Moment, durch das die Entstehung der Gattung Tragikomödie angestoßen wurde. Dass das Tragische in der Moderne nicht mehr möglich sei, sondern vom Komischen überboten werde, dieser von Hebbel $^{125}$ über Vischer ${ }^{126}$ bis hin zu Dürrenmatt ${ }^{127}$ weitergereichte Topos datiert, wohl unfreiwillig, bis auf die Emilia zurück. Erst in ihrer Folge konnte Jakob Michael Reinhold Lenz den an und für sich tragischen Stoff seiner Soldaten mit der Gattungsbezeichnung »Komödie« versehen. Tatsächlich wird die Opferdrift der Protagonistin Marie bzw. Mariane auch durch die im Zuge der Empfindsamkeit akut gewordene Imitation der Literatur durch das Leben ausgelöst, ein Verhalten, das ins komische Register zumindest hineinspielt. ${ }^{128}$ Dennoch kann Marie im Stück als exemplarisches, als »unglücklich[es] Schlachtopfer « bezeichnet werden. ${ }^{129}$ Als ein solches wurde sie dem intertextuell gewieften Zuschauer oder Leser schon zuvor designiert: Nämlich mit der »Zitternadel«, die ihr der Verführer Desportes in der dritten Szene des ersten Akts galant verehrt hatte und die an Emilias Haarnadel erinnert. ${ }^{130}$ Nicht allein in diesem Drama sollte Lenz in allem jugendbewegten Enthusiasmus die geschlechteranthropologische Aufladung der victima umarmen. Anderswo nennt er ganz in Lessings Sinne das weibliche das »bessere Geschlecht «131, es sei »das Geschlecht, das allein aus Männern Menschen machen und durch die Liebe ihren regellosen Kräften und Fähigkeiten Gestalt geben kann $\ll \cdot{ }^{132}$

\footnotetext{
(Anm. 1), 2, erkennt, dass Marquards Übertribunalisierungsthese den Gang der Rezeptionsgeschichte der Emilia vorzeichnet.

125 Vgl. Friedrich Hebbels Vorrede »An Heinrich Theodor Rötscher« zu seiner Tragikomödie Ein Trauerspiel in Sizilien. Hebbel, Werke (Anm. 29), I, 387-389.

126 Vgl. Verf., »Die Tücke des Objekts: Friedrich Theodor Vischers >Auch Einer««, in: Susanne Scholz, Ulrike Vedder (Hrsg.), Handbuch Literatur \& materielle Kultur. Handbücher zur kulturwissenschaftlichen Philologie, hrsg. Claudia Benthien, Ethel Matala de Mazza, Uwe Wirth, VI, Berlin, Boston 2019, 248-257, hier: 253.

127 Vgl. Friedrich Dürrenmatt, »Theaterprobleme« (1954), in: Ders., Gesammelte Werke, VII: Essays, Gedichte, Zürich 1996.

128 Als sich Werther umbringt, liegt bekanntlich die Emilia Galotti auf dem Schreibtisch. Das hatte Goethe nicht als Huldigung gemeint.

129 Vgl. Jakob Michael Reinhold Lenz, Die Soldaten, in: Ders., Werke und Briefe in drei Bänden, hrsg. Sigrid Damm, I, 245 (Szene V/5).

${ }^{130}$ Lenz (Anm. 129), I, 197.

131 Lenz, Zerbin oder Die neuere Philosophie, in: Ders., Werke (Anm. 129), II, 357.

132 Lenz, Verteidigung des Herrn W. gegen die Wolken, in: Ders., Werke (Anm. 129), II, 732.

133 Friedrich Wilhelm Gotter, Mariane. Ein bürgerliches Trauerspiel in drey Akten, München 1782, 35.
} 
Tatsächlich ist es auf die Emilia zurückzuführen, dass sich auf den Bühnen jetzt »überall die Szene des Opfers « abspielt. ${ }^{133}$ »Überall die Szene des Opfers «, das ist ein Zitat aus dem bürgerlichen Trauerspiel Mariane von Friedrich Wilhelm Gotter von 1782. Ich betone den Ausdruck »Szene«, weil mit ihm wiederum ein dramenpoetologischer Begriff, der Begriff der Szene, auf der Szene selbst gebraucht wird. Ähnlich wie Lessing verbindet auch Gotter die Gender-Reflexion mit einer des Genres, als victima in der Position des sacrificiums figuriert auch bei ihm eine unschuldige Frau. Und wiederum wird das Opfermotiv negativ andrologisch flankiert: »Daß mein Sohn weiter nichts als ein brausender Jüngling wäre!«, sagt gleich zu Beginn eine Mutter über ihr missratenes Kind. »Aber, leider, ist er schon zu sehr Mann! Diese Härte der Seele, bei äußerlicher Geschmeidigkeit und Sanftmut [...] «. ${ }^{134}$ Männlichkeit, davon redete man bereits damals, sei toxisch, sie vergifte die Gesellschaft, wie die Gesellschaft umgekehrt Frauen, aber auch Männer selbst vergifte.

Gotters Drama ist heute vergessen, und das nicht zu Unrecht. Aber gerade sein epigonaler Charakter macht klar, dass sich die literarische Nobilitierung des weiblichen Opfers um 1780 längst als Mainstream etabliert hat. Emilias Einsetzungsworte von der gebrochenen Rose wurden unmittelbar von ihrem Vater wiederholt und bald darauf, wie Cornelia Mönch ermittelt hat, in mehr als 31 Dramen. ${ }^{135}$ Insbesondere trachteten die Stürmer und Dränger Lessing und einander förmlich zu überbieten, indem sie ein ums andere Mal »die leidende Frau« auf die Bühne bringen. Die leidende Frau, so heißt ein einschlägig betiteltes Drama von Friedrich Maximilian Klinger. In ihm stirbt, erstmals, eine bürgerliche Ehefrau, umworben von einem gewissenlosen Adligen, den empfindsamen Opfertod. Sie stirbt ihn aus Liebeskummer und aus Schuldgefühl, und vor allem zitiert sie zuvor aus Emilia Galotti: »Ich habe die Rose gepflückt, ehe sie der Sturm entblättert. Es steht in einem Trauerspiel, glaub ich« (V/1). Auch hier also der Verweis auf das Tragische in der Tragödie selbst!

Die Populärformate des bürgerlichen Rührstücks und des Familiengemäldes wurden maßgeblich von Lessing, und zwar durch dessen Diderot-Übersetzung auf den Erfolgsweg gebracht. In ihnen führen Anhänger von Lessings Dramaturgie wie Gustav Wilhelm Friedrich Großmann oder Otto Freiherr von Gemmingen Fälle, die dem tragischen Konflikt der Emilia vergleichbar gelagert sind, einer glücklichen Lösung $\mathrm{zu}$ - und das auch, um mit trivialen Mitteln noch positive Bilder vom Hausvater malen zu können. ${ }^{136}$ Noch 1796 bedient sich August von Kotzebue in seinem Abolitionsdrama Die Negersklaven aller Muster des Rührstücks. Er ruft mit Emilias Rose das Genre des bürgerlichen Trauerspiels auf, und er lässt eine weiße Figur als Repräsentanten der Schuldgruppe Lessings Frauenlob durch ein Lob der anderen

\footnotetext{
134 Gotter (Anm. 133), 7.

135 Mönch (Anm 5), 302 ff., listet, ohne Vollständigkeit zu beanspruchen, allein 31 Dramen aus dem Zeitraum 1772-1796 auf, die mithilfe von Adaptionen der zentralen Rosenmetapher direkten Bezug auf die Emilia nehmen. Die Liste wäre leicht zu verlängern.

136 Vgl. Verf., »Die Entsorgung des Hausvaters« (Anm. 3).

137 Kotzebue, Die Negersklaven, 84. Vgl. Irmtraud Hnilica, »Vom bürgerlichen Trauerspiel zum Abolitionsdrama: Kotzebues Die Negersklaven«, in Julia Bohnengel, Thomas Wortmann (Hrsg.), »Die deutsche Freiheit erdolcht! «Leben, Werk und Tod August von Kotzebues (im Druck).
} 
Ethnie überbieten: »[I]ch glaubte immer, Gott habe aus Einem Stoffe uns geformt; ich irrte mich, er schuf euch [die im Titel so genannten Negersklaven] besser! «137

Überall also die Szene des Opfers! Bekundet sich in der von Lessing mit angekurbelten dramatischen Opferkonjunktur aber nicht eine Befallsstelle im großen Projekt der Aufklärung, in der Opferkritik? In deren Geiste konnte Cesare Beccaria bekanntlich die Todesstrafe kritisieren, nicht zuletzt, indem er ihre Dysfunktionalität erwies. In ihrer opferkultischen, zumal aufs Spektakel berechneten Dimension habe sie nicht selten Mitleid für den Delinquenten erregt, für das »menschliche Schlachtopfer«. Beccaria deutet den Verurteilten als Schlachtopfer (vittima), der zur Opferung (sacrifizio) für den unersättlichen Götzen des Despotismus bestimmt sei. »Die Todesstrafe ist für den größten Theil der Zuschauer weiter nichts, als ein blutiger Aufzug, ein Menschenopfer, ein Schauspiel für Müßige und für Etliche die Veranlassung eines mit Unwillen vermischten Mitleidens. «138 Ein systematischer Abgleich zwischen Beccarias Diskurs über die Wirkung der Strafen und Lessings Ästhetik wäre ein Desideratum. Inwiefern münzt Letztere den von Beccaria beschriebenen Wirkmechanismus für das dargestellte Opfer aus? Inwiefern verwandelt sich die aufgeklärte Opferkritik in einen ästhetischen Opferkult? Zumindest erklärt Lessing ja Moralität zur theatralischen Kategorie, wenn er lehrt, der mitleidigste sei der beste Mensch. Wenn man nun statuiert, es gebe nicht nur den guten, sondern den besseren und gar den besten Menschen, trägt man dann nicht die mimetische Rivalität ins Feld der Moralität hinein? Lessings Lehre vom Mitleid mag menschenfreundlich erscheinen. Aber impliziert sie nicht eine heikle Ästhetisierung des Moralischen? Befeuert sie nicht den Wettbewerb um die vorderen Moralplätze? Wenn man das Theater als moralische Anstalt begreift, verwandelt sich Moralität leicht in eine theatralische Veranstaltung. Es gäbe also Anlass, über die dunkle Seite der Empathie zu sprechen. ${ }^{139}$ Lessing selbst hat die Dimension des Selbstgenusses im Mitleid durchaus erkannt, als er 1755 von den »Tränen des Mitleids, und der sich fühlenden Menschlichkeit« als der ausschließlichen »Absicht des Trauerspiels« sprach. ${ }^{140}$ In Goethes Wahlverwandtschaften wird die Figur der Ottilie ihr »Mitleiden gegen [s]ich selbst wenden« und sich, obschon Täterin, in der Ästhetik des Opfers einrichten. ${ }^{141}$

Vielleicht kann man die Dramatik der Klassik auch vor diesem Hintergrund als Deeskalationsmaßnahme verstehen. Goethes Iphigenie knüpft noch einmal affirmativ an die Opferkritik der Aufklärer an, nicht ohne die zeitgenössische Geschlechteranthropologie aufzurufen, wenn nämlich die Titelheldin eingangs »der Frauen Zustand [...] beklagenswert« nennt. Am Ende lässt das Drama »Gewalt und List, der Männer höchster Ruhm/ [...] durch die Wahrheit dieser hohen Seele beschämt«

\footnotetext{
138 Des Herren Marquis von Beccaria unsterbliches Werk von Verbrechen und Strafen. Auf das Neue selbst aus dem Italiänischen übersetzet mit durchgängigen Anmerkungen des Ordinarius zu Leipzig Herren Hofrat Hommels, Breslau o.J. [1778], 137.

139 Vgl. Fritz Breithaupt, Die dunklen Seiten der Empathie, Berlin 2017.

140 Lessing, Vorrede zu »Des Herrn Jakob Thomsons sämtliche Trauerspiele«, in: Ders., Werke (Anm. 24), IV, 144.

141 Vgl. Verf., »Für sich und andere vielleicht« (Anm. 3).
} 
erscheinen. ${ }^{142}$ Noch von diesem, seinem eigenen Opferdrama, von der $»$ verteufelt human[en] « Iphigenie ${ }^{143}$ wird sich Goethe mehrfach distanzieren, wie er sich auch noch 1827 in seiner Nachlese zu Aristoteles' Poetik vehement gegen die wirkungsästhetische Auffassung der Katharsis wendet. Lessings Name muss in diesem Kontext gar nicht mehr fallen. ${ }^{144}$

Im klassischen Drama geht es um eine Reflexion der Dramaturgie des Opfers selbst, und damit auch um Distanz gegenüber seiner Theatralität. Schiller hatte 1792 den Grund des Vergnügens an tragischen Gegenständen noch darin ausgemacht, das dramatische Opfer appelliere an das »Gefühl einer moralischen Zweckmäßigkeit «. ${ }^{145}$ Ich betone das »Gefühl«, eben weil Schiller die moralische Zweckmäßigkeit nur gefühlt sein lässt. Dem Verdacht, im Zeichen des Opfers überantworte das Theatralische Moralität der Sphäre des Scheins, hat Schiller ein ganzes Stück gewidmet. In der 1801 uraufgeführten Maria Stuart geht es in der Rivalität der beiden Königinnen explizit auch um Geschlechteranthropologie. Wenn aber die weibliche Natur als Modell einer milden und gerechten politischen Herrschaft ins Spiel gebracht wird, ${ }^{146}$ geschieht das wohlgemerkt auf der Bühne, und es geschieht in politischen Kontexten, im Zuge des dramatischen Konflikts, zu dessen Ende Maria Stuart ihre Hinrichtung als tragische Opferung zelebriert. Auf der Ebene der Handlung wird um das Opfer gerungen, mit ihm Politik betrieben, zumal in geschlechtersemantischer Metacodierung: Und das wird auf der Ebene der Darstellung, das wird auf der Bühne selbst dramaturgisch reflektiert. Der dramatische Konflikt ist auch ein Konflikt über die opferpolitische Dimension der Hinrichtung Maria Stuarts zwischen Legitimität, Staatsräson und öffentlicher Meinung, Konkurrenz- und Geschlechterpsychologie.

Die dramatischen und dramaturgischen Reflexionen der Theatralität des Opfers haben zu seiner Proliferation beigetragen. Und sie gehen weiterhin mit geschlechteranthropologischen Semantisierungen einher. »Opfer!« lautet das erste Wort in Friedrich Hebbels erstem Drama Judith, an dessen Ende zwar der Mann, Holofernes, stirbt. Hebbel, der sich, wie angedeutet, an der Emilia und ihrer Dramaturgie gerieben hatte, lässt hingegen die überlebende Attentäterin Judith die tragische Position bekleiden.

Auch anderswo klingen die Nachbeben von Lessings Theatercoup kaum ab. Das Opfer der empfindsamen Unschuld wird ein ums andere Mal auf der Opernbühne zelebriert. Einer Nachfahrin Emilias begegnen wir in der Götterdämmerung. Richard Wagner, dessen Schwester Rosalie Schauspielerin und zeitweilig eine erfolgreiche Darstellerin der Emilia gewesen war, stilisiert die Figur der Brünnhilde zur Weltenrichterin. Ihr Selbstopfer in Gestalt einer Selbstverbrennung gibt mit der Götterwelt eine ganze Weltordnung der Vernichtung anheim. Ein Zusammenhang zwischen Empfindsamkeit und Gewalt, wie er schon in Donizettis auf Walter Scott basie-

\footnotetext{
142 Goethe, Iphigenie auf Tauris, V. 24, bzw. V. 2142 f. Goethe (Anm. 75), III.1, 162, 220.

143 Goethe, Briefwechsel mit Schiller, Brief vom 19. Januar 1802, Goethe (Anm. 75), VIII.1, 874.

144 Goethe (Anm. 75), XIII.1, 340.

145 Friedrich Schiller, Über den Grund des Vergnügens an tragischen Gegenständen, in: Ders., Sämtliche Werke in 5 Bänden, hrsg. Peter-André Alt, V, 358-372, hier: 369. Hv. U. St.

146 Friedrich Schiller, Maria Stuart II/3, V. 1343 f., in: Ders., Werke und Briefe in zwölf Bänden, V, hrsg. Matthias Luserke-Jacqui, 53.
} 
render Lucia di Lammermoor festzustellen war, und im Sprechtheater natürlich in Kleists Penthesilea. Es ist kein Zufall, dass Flauberts Emma Bovary eine Aufführung von Donizettis Oper erlebt, ebenso wenig, dass Effi Briest in einem Liebhabertheater an der Aufführung eines nicht eben subtil »Ein Schritt vom Wege« benannten Lustspiels mitwirkt. Nach Goethes Wahlverwandtschaften sind dies die wichtigsten Beispiele für die prosaische bzw. romaneske Beobachtung und Distanzierung der Theatralität des Opfers im 19. Jahrhundert. Sowohl Madame Bovary als auch Effi Briest zelebrieren ihr Sterben in opferkultischen bzw. opfersemantischen Kontexten.

Das wäre ausführlich zu rekonstruieren. Schon jetzt mag die Skizze plausibel erscheinen lassen, dass Emilias Auftrag erfolgreich ausgeführt wurde. Mit dem ersten besten Stahl hat Odoardo ihr zum zweiten das Leben gegeben. Als unschuldiges Opfer erlebt die heilige Emilia ihr zweites Leben in den Deutungen, die sich im Lessing'schen Sinne erschüttert und von Furcht und Mitleid bewegt diesem Tod widmen. Das sakrifizielle Ritual stellt sicher, dass das Gedächtnis der victima stets erneut begangen wird.

\section{VI.}

Die Frage nach der Theatralität des Opfers ist kulturell höchst brisant. In ihr begegnet eine einschlägig literaturwissenschaftliche einer kultur- und sozialgeschichtlichen Problematik mit Aktualitätspotenzial. Trifft es zu, dass mit Lessings Emilia (und ihren Schwestern) die Engführung von Opferschaft und Weiblichkeit als kulturelles Modell etabliert wurde? Die überwältigende Rezeption dieses so merkwürdig souverän und zugleich so fragwürdig konstruierten Dramas legt dies nahe. Dass sein tragischer Schluss trotz aller schon von den Zeitgenossen bemerkten Mängeln eine derartige Wirkung ausüben konnte, ist ohne dramenpoetologische und literaturwissenschaftliche Mittel kaum zu erklären. Aber allein mit ihnen eben auch nicht. Seine bis heute anhaltende Suggestivkraft ist ohne eine kulturelle Tendenz kaum zu begreifen, in der Positionen der Moralität überhaupt geschlechtersemantisch codiert wurden und sich dann nicht länger männlich, sondern weiblich definierten. Die lateinische virtus, vom Genus her Femininum, beinhaltete noch den vir, den Mann. Gewiss, als jetzt im 18. Jahrhundert geschlechteranthropologische Modelle wie Pilze aus dem Boden schossen, geriet die Gemengelage unübersichtlich. Es gab nicht wenige Positionen, die Weiblichkeit abwerteten, ihr gleichsam in einer Sonderanthropologie defizitäre Qualitäten zuschrieben. ${ }^{147}$ Erstaunlich aber mutet an, mit welcher nur geringfügig getrübten Einhelligkeit bald das weibliche als das moralische Geschlecht begriffen werden sollte. ${ }^{148}$ Dabei mag, wie oft eingewandt wurde, die Idealisierung der Weiblichkeit realhistorische Marginalisierungen von Frauen bloß flankiert haben. Aber genau darum ging es doch in der Engführung von Opfer- und Geschlechtersemantiken: Auf der Ebene der Semantik, so z.B. durch das

\footnotetext{
147 Claudia Honegger, Die Ordnung der Geschlechter. Die Wissenschaften vom Menschen und das Weib 1750-1850, München 1996 [erstmals Frankfurt a.M. 1991].

148 Lieselotte Steinbrügge, Das moralische Geschlecht. Theorien und literarische Entwürfe über die Natur der Frau in der französischen Aufklärung, Stuttgart 1992.
} 
vom Opfer ausgehende Empathiegebot, kulturelles Kapital für die Benachteiligten zu generieren, das sich auf längere Sicht auszahlen sollte. Wenn man annimmt, dass soziale Veränderungen der Vorbereitung durch gesellschaftliche Semantiken bedürfen, und um die geht es ja hier, kann man nicht umhin zuzugestehen, dass sich der Mainstream der Geschlechtersemantik der Moderne eben nicht misogyn, sondern gynophil ausgenommen hat. Es ist diese Semantik, die sich zumindest in der schönen Literatur überwältigend durchgesetzt hatte. »Das weibliche Geschlecht«, sagt der Erzähler in Goethes Wahlverwandtschaften, übt »eigentlich das Regiment [aus], dem sich in der gesitteten Welt kein Mann zu entziehen wagt «. ${ }^{149}$ Aus der bis weit ins 19. Jahrhundert und darüber hinaus, bis hin zu Dürrenmatt oder Jelinek ausstrahlenden Erfolgsgeschichte des bürgerlichen Trauerspiels erhellt mithin eine prekäre kulturelle Wirkmächtigkeit von Literatur. Schon im 18. Jahrhundert hat sie das Opfer als neuen Helden definiert. Sie hat eine Semantik gestiftet, ohne die die Transformation einer bürgerlichen Kultur der Würde in eine postbürgerliche Opferkultur ${ }^{150}$ kaum vonstattengegangen wäre. Das ging mit einer gewissen Vergesslichkeit einher. Die sakrifiziellen Wurzeln des Opfers wurden immer weniger bedacht. Campbell und Manning sprechen stets vom »victim«, kaum aber vom »sacrifice«. Dieser Übergang spiegelt sich in einer weiteren semantischen Verschiebung. Zwar habe sich im Deutschen erst nach 1945 die Rede vom »Opfer sein« eingebürgert. Vorher seien Opfer »erbracht « worden. ${ }^{151}$ Und tatsächlich war bis weit ins 20. Jahrhundert hinein noch die Rede vom Kriegsopfer auf Handlungsmacht bezogen, es war oft das Opfer, das Soldaten oder die Bevölkerung erbrachten. ${ }^{152}$ Im sakrifiziellen Opfer, das hat zuletzt Terry Eagleton betont, vollzieht sich der Übergang von Schwäche zu Stärke. ${ }^{153}$ Dass sich im Zuge gesellschaftskritischen Engagements allgemeine Viktimologien etablieren konnten, ${ }^{154}$ dafür war nicht zuletzt eine Mobilisierung von Empathiepotenzialen erforderlich, zu der die literarischen Bewirtschaftungen der Gefühle, darunter Lessings Mitleidsästhetik, nicht unbeträchtlich beigetragen haben. Mit unbedingt begrüßenswerten, aber eben nicht nur ungetrübten Folgen.

Im Rahmen der erstaunlichen Bereitschaft der modernen Gesellschaft, sich selbst zu kritisieren, konnte die Geschlechterdifferenz eine gewichtige Funktion übernehmen. An Männern wird die Differenz von Gesellschaft und Interaktion, Arbeitswelt und Häuslichkeit, Entfremdung und Sinngebung sinnenfällig. ${ }^{155}$ Weil der Mann hinaus musste ins feindliche Leben, etablierte sich die Kritik an der schlechten Äußerlichkeit des gesellschaftlichen Lebens, an Profitstreben, Entfremdung, Verstellung,

\footnotetext{
149 Goethe (Anm. 75), IX, 447.

150 Vgl. Campbell, Manning (Anm. 43).

151 Christian Kohner-Kahler, »Müde Helden. Subjektivierungsprozesse in ängstlichen Zeiten«, texte. psychoanalyse. ästhetik. Kulturkritik 4 (2009), 32-55.

152 Svenja Golterman, Opfer. Die Wahrnehmung von Krieg und Gewalt in der Moderne, Frankfurt a. M. 2017, 157f. u.Ö.

153 Terry Eagleton, Radical Sacrifice, New Haven, London 2018, 8.

154 Goltermann (Anm. 152), $180 \mathrm{f}$.

155 Vgl. John Tosh, »Was soll die Geschichtswissenschaft mit Männlichkeit anfangen? Betrachtungen zum 19. Jahrhundert in Großbritannien«, in: Christoph Conrad, Martina Kessel (Hrsg.), Kultur \& Geschichte. Neue Einblicke in eine alte Beziehung, Stuttgart 1998, 160-208, hier: 178 u.Ö.
} 
Macht, Hegemonie und Unterdrückung als Kritik an der Männlichkeit. Das setzte sich in der in den Men's Studies so einflussreichen Theorie der hegemonialen Männlichkeit fort. Als Raewyn Connell beklagte, »die Ergebnisse [einer durch die männliche Perspektive geprägten Wissenschaft von der Männlichkeit; U. St.] werden genauso verzerrt sein, als wenn Imperialisten die Rassenthematik oder Kapitalisten den Kapitalismus erforschen würden $\ll,{ }^{156}$ stellte sie eine Gleichung zwischen Männlichkeit und all dem auf, was sie an Übeln in der Moderne wahrnahm. Wie zweckmäßig aber wäre die lange Tradition einer zumal von Männern betriebenen Kritik des Männlichen für eine ihm unterstellte Hegemonie? Diese Frage konnte Connell nicht beantworten.

Eine sinnerfüllte Sozialität hingegen fand, orientiert an der Kommunikation in Familie oder Salon, ihr Modell in idealisierter Weiblichkeit. Das Reden über Geschlecht, so Kucklick, übernimmt in der Moderne eben auch die Funktion, gesellschaftsstrukturelle Defiziterfahrungen zu symbolisieren: Geschlecht bedeute die Supercodierung der Differenz von Interaktion und Gesellschaft. ${ }^{157}$ Die Differenz von Interaktion und Gesellschaft aber war insbesondere in der anbrechenden kulturellen Moderne der Gegenstand schlechthin des Dramas. ${ }^{158}$

Welche Konsequenzen ergeben sich aus diesen Befunden für die Literaturwissenschaft? In den Spielarten der Humanities, die sich mit ästhetischen Gegenständen befassten, um sie opferpolitisch zu lesen, konnte sogar die Darstellung des weiblichen Opfers, als handelte es sich um eine reale Opferung, als Ausdruck männlichen Machtbegehrens denunziert werden. Nicht wenige Interpretinnen und Interpreten meinten, das Frauenopfer, gerne spricht man auch vom >Femizid <, dokumentiere oder zementiere die reale Unterdrückung der Frau, es verrate die Schau- oder Opferlust eines sich überlegen wähnenden Geschlechts. ${ }^{159}$ Um aus der Position des von Männern dargestellten weiblichen Opfers eine patriarchale Erniedrigung des Weiblichen herauszulesen, wurde gar von einer »ästhetischen Hinrichtung « gesprochen. ${ }^{160}$ Doch verwechselt dieser Vorwurf erkennbar die Darstellung mit dem Dargestellten. Wenn man das Opfer und zumal die ihm verbundenen Darstellungsstrategien nicht nur als victima, sondern als sacrificium begreift, erkennt man vielleicht, dass die Darstellung des Opfers nicht etwa seine patriarchale Erniedrigung dokumentiert. Sie betreibt vielmehr seine »Darhöhung «, um an Buber und Rosenzweig zu erinnern.

Seit sich bürgerliches Trauerspiel und Geschlechteranthropologie der Moderne die Hände reichten, akkumuliert die Darstellung oder die »Darhöhung« unschuldiger Weiblichkeit als Opfer das symbolische Kapital, das in späteren Emanzipationskämpfen Zinsen trägt. Wer Emilia und ihre Schwestern als Zeugen aufruft, um

\footnotetext{
156 Raewyn W. Connell, Der gemachte Mann. Konstruktion und Krise von Männlichkeiten, 4. Aufl., Wiesbaden $2015,51$.

157 Vgl. Kucklick (Anm. 88), $209 \mathrm{ff}$.

158 Dietrich Schwanitz, Systemtheorie und Literatur. Ein neues Paradigma, Opladen 1990, 99-129.

159 Vgl. z.B. Catherine Clément, Die Frau in der Oper. Besiegt, verraten und verkauft, München 1994 (Paris 1979). Elisabeth Bronfen, Nur über ihre Leiche. Weiblichkeit, Tod und Ästhetik, München 2004.

160 Andrea Rudolph, »Frauen auf dem Altar der Humanität. Zur >Geschlechterklausel< in Friedrich Hebbels Dramen«, in: Ester Saletta, Christa Agnes Tuczay (Hrsg.), Geschlechterkampf oder Geschlechterdialog: Friedrich Hebbel aus der Perspektive der Genderforschung, Berlin 2008, 93.
} 
die moderne Gesellschaft als patriarchal und Männlichkeit als hegemonial zu charakterisieren, mobilisiert Mitleid und kämpft für eine sympathische Sache, gewiss. Dabei wird aber die semantische Ebene, das symbolische Kapital, von dem man zehrt, aus der Rechnung ausgelagert. Führt man es dagegen mit auf, fällt die Bilanz der Moderne positiver, gewiss realistischer und damit vielleicht auch ein wenig gerechter aus. Um das tiefenscharf zu sehen, müsste man genauer erhellen, inwiefern das dargestellte Opfer die Stellvertretung derjenigen Stellvertretung bedeutet, die das reale Opfer bereits ist: Ist es die explizite Darstellung, die den Darstellungscharakter schon des realen Opfers erhellt? Oder trägt sie die Energien weiter, nährt sie die Leidenschaften, die das Opfer entfacht? Wir müssen vielleicht noch besser begreifen, was »darstellen« heißt und, vor allem, was es bedeutet, darzustellen.

Funding Open Access funding enabled and organized by Projekt DEAL.

Open Access Dieser Artikel wird unter der Creative Commons Namensnennung 4.0 International Lizenz veröffentlicht, welche die Nutzung, Vervielfältigung, Bearbeitung, Verbreitung und Wiedergabe in jeglichem Medium und Format erlaubt, sofern Sie den/die ursprünglichen Autor(en) und die Quelle ordnungsgemäß nennen, einen Link zur Creative Commons Lizenz beifügen und angeben, ob Änderungen vorgenommen wurden.

Die in diesem Artikel enthaltenen Bilder und sonstiges Drittmaterial unterliegen ebenfalls der genannten Creative Commons Lizenz, sofern sich aus der Abbildungslegende nichts anderes ergibt. Sofern das betreffende Material nicht unter der genannten Creative Commons Lizenz steht und die betreffende Handlung nicht nach gesetzlichen Vorschriften erlaubt ist, ist für die oben aufgeführten Weiterverwendungen des Materials die Einwilligung des jeweiligen Rechteinhabers einzuholen.

Weitere Details zur Lizenz entnehmen Sie bitte der Lizenzinformation auf http://creativecommons.org/ licenses/by/4.0/deed.de. 